\title{
A reassessment of the phylogeny and circumscription of Zaluzianskya (Scrophulariaceae)
}

Jenny K. Archibald ${ }^{\mathrm{a}}$, ${\text {, Jacqueline } \text { Cook }^{\mathrm{b}} \text {, Bruce Anderson }}^{\mathrm{c}}$, Steven D. Johnson ${ }^{\mathrm{d}}$, Mark E. Mort $^{\mathrm{a}}$

${ }^{a}$ Biodiversity Institute and Department of Ecology and Evolutionary Biology, University of Kansas, Lawrence, Kansas 66045, USA

${ }^{b}$ Rush-Copley Medical Center, Aurora, Illinois, 60504, USA

${ }^{c}$ Department of Botany and Zoology, University of Stellenbosch, Private Bag X1, Matieland, 7602, South Africa

${ }^{d}$ School of Life Sciences, University of KwaZulu-Natal, Pietermaritzburg, South Africa *Corresponding author: jkarchibald@yahoo.com 
Abstract The genus Zaluzianskya (Scrophulariaceae s.s.) encompasses a diversity of traits, such as flowers ranging from 4 to $60 \mathrm{~mm}$ in length with various patterns of color and indumentum. However, this diversity, as described by the current taxonomic circumscription of Zaluzianskya, is an underestimate. The boundaries of this genus require expansion via incorporation of species from other genera and recognition of unnamed species. This study advances prior molecular phylogenies for the southern African genus through the addition of DNA regions and an up to $70 \%$ increase in population sampling, targeting specific taxa. Results are presented from analyses of five DNA regions, including nuclear ITS and four rapidly evolving chloroplast regions ( $\operatorname{trnF}, r p l 16, r p s 16$, and trnS-trnfM). Our primary result is that several species of Phyllopodium should be included within Zaluzianskya, but that other species of Phyllopodium group with Polycarena, indicating the need for further phylogenetic work on these genera. Preliminary support for the incorporation of Reyemia into Zaluzianskya is reinforced here by the first molecular analysis to include both species of Reyemia and a strong sampling of species across Zaluzianskya and tribe Limoselleae. Two disjunct species of Zaluzianskya are also confirmed as members of this genus. Finally, a broad sampling of 21 populations of Z. microsiphon establishes their phylogenetic division into two to five separate lineages. Hybridization, coevolution, and cryptic speciation may each play a role in the evolution of Z. microsiphon. Further resolution within a clade comprising sections Nycterinia and Macrocalyx is needed to better understand their relationships. 
Keywords: Disjunct distribution; Phyllopodium; Reyemia; Scrophulariaceae; South ; Zaluzianskya

\section{Introduction}

With a distribution centered in South Africa and including the botanical hotspot of the Cape Floristic Region (Cowling et al., 2009), the ca. 58 species of Zaluzianskya F.W. Schmidt (Scrophulariaceae, tribe Limoselleae; Table 1) provide a compact sample of morphological and ecological diversity, including variation in traits such as floral form, life history, and habitat preference (Hilliard, 1994; Manning and Goldblatt, 2010). For example, species include day-flowering, minute annuals of desert habitats and nightflowering shrublets of moist high-elevation meadows (Fig. 1). This range of characteristics allows study of various evolutionary questions, including those related to morphological evolution (Archibald et al., 2005), hybridization (Archibald et al., 2004; Campbell et al., 2016), coevolution (Anderson and Johnson, 2008), and more general aspects of pollinator-driven floral evolution (Anderson and Johnson, 2006; Anderson et al., 2005; Johnson et al., 2002).

The diversity of the Zaluzianskya lineage appears to be greater than originally estimated. Phylogenetic data provided preliminary support for inclusion of species from other genera such as Reyemia (Archibald et al., 2005; Kornhall et al., 2001; Manning \& Goldblatt 2014); a new species of Zaluzianskya was recently described by Manning and 
Goldblatt (2010); and polyphyly in molecular phylogenies suggests the possibility of unrecognized cryptic species, particularly within Z. microsiphon (Archibald et al., 2005). However, prior studies relating to the placement of Reyemia only included a sample of one of the two species and either had low levels of sampling within Zaluzianskya (Kornhall et al., 2001) or relatively low sampling across tribe Limoselleae (Archibald et al., 2005), both of which are important for a thorough assessment of the placement of this species. Confirmation of the polyphyly of Z. microsiphon also requires greater sampling, with the prior phylogenies only including three populations (Archibald et al., 2005). In addition to these potential expansions of Zaluzianskya, the relationships of two species of Zaluzianskya that are geographically disjunct from the remainder of the genus have not been tested phylogenetically.

Tribe Limoselleae sensu Kornhall and Bremer (2004) includes Limosella and ca. 25 genera formerly placed in tribes Manuleeae and Selagineae (Hilliard, 1994, 1999; Kornhall and Bremer, 2004). Hilliard (1994, 1999) provided monographs for many of these species. Reyemia was described by Hilliard (1992) to accommodate Zaluzianskya nemesioides Diels plus the new $R$. chasmanthiflora Hilliard, but later molecular analyses suggested that the species were nested within Zaluzianskya. In a tribal-level study, Kornhall et al. (2001) found preliminary evidence that Reyemia chasmanthiflora was nested within Zaluzianskya but only included three species of Zaluzianskya. Archibald et al. (2005) increased sampling in the genus to 23 species to produce the first inference of phylogeny across all sections of Zaluzianskya. They found strong support for the nesting of $R$. nemesioides within Zaluzianskya (99\% bootstrap, BSt), but did not sample $R$. chasmanthiflora and did not have the extensive sampling of other genera in Limoselleae 
of Kornhall et al. (2001). These findings, and the morphological affinity between the two genera, led Manning and Goldblatt (2014) to merge Reyemia back into Zaluzianskya as sect. Reyemia. Our present study retests the phylogenetic placement of Reyemia, including both species of the genus and a broad sampling of species across both Zaluzianskya and Limoselleae. In addition, preliminary analyses indicated that species of Phyllopodium (Limoselleae) are also nested in Zaluzianskya (Archibald unpub.). In the present study, DNA sequences from seven of the 26 species of Phyllopodium allowed a first examination of this possibility. We also expanded our outgroup sampling to include all of the major clades of tribe Limoselleae.

Zaluzianskya is a component of many major biomes in South Africa and extends into the neighboring countries of Lesotho, Swaziland, and Namibia. Only two species occur elsewhere (Hilliard, 1994). One of these, Zaluzianskya tropicalis (sect. Nycterinia), is widespread in Zimbabwe and reaches into Mozambique, while the second, Zaluzianskya elgonensis (sect. Zaluzianskya subsect. Noctiflora), is widely disjunct from its allies. Seemingly known only from two collections, on Mt. Elgon in Uganda and Mt. Kilimanjaro in Tanzania, Z. elgonensis is geographically separated from the rest of its subsection by at least $3000 \mathrm{~km}$ (Hilliard, 1994). Neither of the disjunct species was included in previous molecular phylogenetic analyses, and the biogeographical factors behind their isolated distributions are unknown. Both species were included in the present study.

Prior molecular phylogenetic analyses of Zaluzianskya inferred three major clades (Archibald et al., 2005). Clades 1 and 2 each included members of sections Zaluzianskya and Holomeria, with clade 2 also including Reyemia. Relationships within clade 3, or the 
Nycterinia + Macrocalyx clade, remained obscure, with incomplete resolution and some conflict between gene trees. Johnson et al. (2002) produced a morphological phylogeny for Zaluzianskya sect. Nycterinia, but with generally weak bootstrap support across the clade. In the molecular phylogenies, clade 3 included all sampled members of sect. Nycterinia and the single sampled representative of sect. Macrocalyx. Populations of one species of clade $3, Z$. microsiphon, were broadly separated in these analyses. Chloroplast and ITS data differed in resolution of this clade, with ITS showing no well-supported resolution beyond a division of Z. microsiphon and a strongly-supported sister relationship between the two sections $(\mathrm{BSt}=70)$. The chloroplast tree divided clade 3 into two subclades, one of which included Z. mirabilis (from sect. Macrocalyx), one of three sampled populations of Z. microsiphon, and two other species from sect. Nycterinia (BSt=99). Sampling of Z. microsiphon in the present study has been increased from 3 to 21 populations from across its geographic range in Lesotho and southeastern South Africa (including parts of KwaZulu-Natal, Eastern Cape, Free State, and Mpumalanga Provinces). This allowed more thorough tests of the potential division of this species. A robust phylogenetic framework is important for resolving the circumscription of the Zaluzianskya lineage and for investigating evolutionary patterns and processes. Archibald et al. (2005) sequenced ITS, $\operatorname{trn} L-\operatorname{trn} F$, and $r p l 16$ across the genus. We have augmented those molecular phylogenetic hypotheses with the addition of two gene regions (rps16 and trnS-trnfM) and key taxa and populations. We address three primary questions to improve our understanding of diversity in the Zaluzianskya clade: 1) Is there strong phylogenetic support for the inclusion of both former species of Reyemia and some members of Phyllopodium in Zaluzianskya? 2) How are disjunct species of 
Zaluzianskya related to other members of the genus? 3) Are multiple, cryptic species revealed within Z. microsiphon when many populations are sampled across its range?

\section{Materials and methods}

\subsection{Taxon collection and sequencing}

Fresh leaf material (ca. $20 \mathrm{mg}$ per individual) was collected on silica gel from each newly collected population; voucher information is given in the Appendix. Initially, 116 populations from 46 species were analyzed. This included 99 populations from 29 species of Zaluzianskya, with representatives from each subsection of the genus and both members of sect. Reyemia. Only populations that were successfully sequenced for at least three of the five DNA regions were retained for further analyses (but see discussion below on level 3 analyses). Samples identified as putative hybrids or introgressants by Archibald et al. (2004) were also removed to minimize the potentially confounding influence of horizontal gene flow on phylogenetic inference (McDade, 1992; Soltis et al., 2008). Of the remaining accessions, 52 populations had never previously been sampled in a published phylogeny (see bold accessions in the Appendix). Within Zaluzianskya, 29 species were included, with 2 or 3 populations of most species and 21 populations of $Z$. microsiphon. The two disjunct species were included via DNA extractions done at Kew from herbarium specimens collected in 1966 (Z. tropicalis) and 1970 (Z. elgonensis). Four species were sequenced from Phyllopodium, with three other species (four populations) of that genus added using GenBank sequences (indicated by "GB"). 
Outgroups were chosen based on their phylogenetic proximity to Zaluzianskya in Archibald et al. (2005) and in broader analyses in Scrophulariaceae (Kornhall, 2004; Kornhall et al., 2001).

Further analyses were primarily conducted at three main levels (Table 2). The sampling within Zaluzianskya was similar across these analyses, while the outgroup (OG) sampling varied greatly. Level 1 focused on the Zaluzianskya clade and a few key OGs for five loci. Level 2 included more OG populations but more missing data across the five loci. Level 3 added GenBank sequences to include 23 of the 27 genera of Limoselleae but with fewer (two) loci. Additional analyses were run to determine the influence of key samples with missing data. For example, analyses were run with and without Phyllopodium mimetes (only sequenced for ITS and trnL-trnF, but one of three sampled species of Phyllopodium that are placed within the Zaluzianskya clade) and Trieenea taylorii (only sequenced for ITS, but noted in the Discussion for sharing a number of traits with Zaluzianskya). The inclusion or exclusion of these two taxa did not alter other relationships, and so results are shown with them included. GenBank sequences for Selago canescens came from two individuals listed as GB1 and GB2 in the Appendix. However, initial analyses indicated that each was placed in the same location on the tree, and so they were concatenated in final analyses (indicated as GB12).

Sequencing methods followed those used previously (Archibald et al., 2005). Newly collected DNA was extracted from leaf samples using standard CTAB methods (Doyle and Doyle, 1987; Mort et al., 2001). Sequences were produced for the nrDNA internal transcribed spacer regions (ITS-1 - 5.8S - ITS-2; see Baldwin et al., 1995), and four regions from the chloroplast genome: the trnL intron, $\operatorname{trn} L$ exon, and $\operatorname{trn} L-\operatorname{trn} F$ 
spacer region (hereafter referred to as the $\operatorname{trnL}-F$ region), the $r p l 16$ intron, the rps 16 intron, and the trnS-trnfM intergenic spacer $(\operatorname{trnS}-f M)$. For discussion of the utility of these and other rapidly-evolving cpDNA regions see Shaw et al. $(2005 ; 2007)$ and Mort et al. (2007). Standard primers were employed for PCR: N-nc18S10 and C26A for ITS (Wen and Zimmer, 1996), B49317 (“c") and A50272 (“f') for trnL-F (Taberlet et al., 1991), L16 exon1 and L16 exon2 for rpl16 (Downie et al., 2000), rpS16F and rpS16R for rps16 (Oxelman et al., 1997; Shaw et al., 2005), and trnSUGA and trnfMCAU for trnSfM (Demesure et al., 1995; Shaw et al., 2005).

PCR amplifications ( $25 \mu \mathrm{l})$ consisted of $1 \mu \mathrm{l}$ DNA, $0.2 \mu \mathrm{M}$ of each primer, $3 \mathrm{mM}$ $\mathrm{MgCl}_{2}$, and 1X Bullseye Taq DNA Polymerase Mix (150 mM Tris-HCl pH 8.5, $40 \mathrm{mM}$ $\left(\mathrm{NH}_{4}\right)^{2} \mathrm{SO}_{4}, 0.2 \%$ Tween $20,0.4 \mathrm{mM}$ dNTPs, 0.5 units/ $\mu \mathrm{L}$ Bullseye Taq polymerase, and stabilizer; Midsci, Saint Louis, Missouri, USA). A MyCycler (Bio-Rad, Hercules, California, USA) thermocycler was used with the following settings: 5 min at $94^{\circ} \mathrm{C} ; 35$ cycles of $1 \mathrm{~min}$ at $94^{\circ} \mathrm{C}, 1 \mathrm{~min}$ at $55^{\circ} \mathrm{C}$, and $1 \mathrm{~min}$ at $72^{\circ} \mathrm{C} ; 10 \mathrm{~min}$ at $72^{\circ} \mathrm{C}$. Each thermocycler run included a negative control reaction of $25 \mu l$ with all of the reagents except for the DNA. PCR products were either purified using a PEG clean-up protocol (Soltis and Soltis, 1997) and sequenced by Macrogen, Inc. (Seoul, South Korea), or sent to htSEQ (High-Throughput Genomics Unit, University of Washington, USA) for ExoSAP purification and sequencing. In both cases, sequencing was completed with the same primers as used for PCR amplification.

\subsection{Phylogenetic analyses and hypothesis testing}


Individual contigs were edited, assembled, and aligned using Sequencher (GeneCodes Inc., Ann Arbor, Michigan) and Se-Al v. 2.0a11 (Rambaut, 2002); or Geneious v. 6.1.7 (Biomatters, Auckland, New Zealand) with alignments using MUSCLE settings and adjustments by eye. Gaps were coded as characters using a modified version of the complex indel coding method of Simmons \& Ochoterena (2000), as implemented by SeqState v. 1.32 (IndelCoder: modified complex coding option, Müller, 2005). All chloroplast sequences were concatenated into one data matrix a priori, and the chloroplast and ITS datasets were analyzed both separately and concatenated with maximum parsimony (MP), maximum likelihood (ML), and Bayesian Inference (BI).

Parsimony analyses were conducted in PAUP* v. 4.0b10-x86 (Swofford, 2003) with the heuristic search option, MulTrees, no MaxTrees limit, swapping on all trees, and parsimony options set to collapse branches if minimum length is zero ("amb-"). Uninformative characters were excluded before all analyses and all remaining characters were equally weighted and unordered. One thousand quick searches with random taxon addition and NNI branch swapping were used to locate multiple islands of minimumlength trees, forming a starting pool of trees for more thorough searches employing tree bisection-reconnection (TBR; Maddison, 1991). Separate TBR searches were run in different putative islands and inferred consistent relationships. Relative support for clades was assessed via jackknife analyses (JK; 5000 replicates). PAUP* was set to emulate Jac resampling with character deletion at 37\%. For the concatenated nuclear and chloroplast dataset, analyses were run using both nucleotide and indel characters, nucleotide characters alone, and indel characters alone, for comparison. Results indicated consistent signal between the two types of characters, with one exception that will be discussed. 
Otherwise, only the combined nucleotide and indel analyses will be discussed here. Separate analyses of data from each genome also included both nucleotide and indel characters unless noted otherwise.

Maximum likelihood and BI analyses were conducted on the nucleotide datasets. Given the similarity of their results, only BI analyses will be discussed. Model parameters were estimated using the Akaike Information Criterion (AIC) of jModelTest v. 2.1.3 (Posada, 2008). Bayesian analyses were conducted in MrBayes v. 3.2.1 (Ronquist et al., 2012) and were partitioned by gene region, allowing independent evolutionary models for each. Two runs of metropolis-coupled Markov chain Monte Carlo simulations each used four linked chains (three heated and one cold) and default priors for all model parameters. The final analyses were halted when the average standard deviation of split frequencies was below 0.001 . After a burn-in of $25 \%$, parameter values were sampled every 10,000 generations. Convergence was assessed using Tracer v. 1.6 (Rambaut and Drummond, 2007) and AWTY (Nylander et al., 2008; Wilgenbusch et al., 2004; "compare" and "cumulative" utilities).

Topological incongruence was assessed by visually comparing the well-supported nodes from each analysis, considering nodes with at least $70 \%$ jackknife support (see Kellogg et al., 1996; Mason-Gamer and Kellogg, 1996) or 0.95 posterior probability (Simmons, 2004). In general, any support values at those levels or above are considered "strong" in this paper. Alternate phylogenetic hypotheses were tested using approximately unbiased (AU) tests in Consel (Shimodaira, 2002), using the concatenated level 1 and level 2 datasets. Candidate trees for AU tests were produced in Garli v. 0.96 (Zwickl, 2006) via unconstrained ML and bootstrap analyses (500 replicates) as well as 
those constrained to include or exclude clades of interest (100 - 500 replicates).

Conclusions were consistent across multiple runs of Consel with differing candidate tree sets. Final AU p-values are from runs using all candidate trees from unconstrained and constrained ML and bootstrap analyses.

\section{Results}

In most cases, analyses produced concordant results regardless of optimality criterion (MP or BI), DNA loci (concatenated or separate), or taxon sampling (levels 1, 2, or 3); exceptions will be noted. Dataset characteristics are described in Table 2. Minimal effective sample sizes were greater than 700 for each parameter in all BI analyses and potential scale reduction factors were all 1.000. The identification of three main clades

within Zaluzianskya (clades 1, 2, and 3) and the relationships among them were as found by Archibald et al. (2005), with some complications regarding clade 2 explained below. Figure 2 summarizes the inferred evolutionary relationships and clade support among Zaluzianskya and outgroups, while Fig. 3 focuses on phylogenetic relationships within Zaluzianskya.

\subsection{Relationships among genera and placement of other genera within Zaluzianskya}

All phylogenetic analyses placed the monophyletic sect. Reyemia within Zaluzianskya with strong support. Its connection with clade 2 was supported or not contradicted by all analyses, with weakest support from cpDNA analyses. Three species of Phyllopodium were also strongly placed within the Zaluzianskya clade, whereas the 
other four sampled species of Phyllopodium were placed in the outgroup near Polycarena. Only level 3 analyses included all three of the species of Phyllopodium that nest within Zaluzianskya, and they resolved Ph. mimetes and Ph. cf. cephalophorum as sister with strong support, with these two species in turn weakly to strongly sister to the remainder of clade 2. Phyllopodium cordatum was strongly resolved as sister to clade $2+$ 3 by concatenated and most ITS analyses but in a polytomy with clades 2 and 3 (and $P h$. mimetes, if sampled) by cpDNA analyses. In contrast, the MP-ITS analyses with low outgroup (OG) sampling weakly to moderately inferred $P h$. cordatum as sister to the remainder of the Zaluzianskya clade. Bayesian analyses of those ITS datasets or MP-ITS analyses without indel characters instead placed Ph. cordatum within the Zaluzianskya clade. Primarily one indel character seems to give the weak support for excluding $P h$. cordatum from the rest of this clade. The signal across ITS and certainly in combination with cpDNA characters nests Ph. cordatum deeper within Zaluzianskya. Regardless, all analyses showed that $P$. cordatum groups with Zaluzianskya rather than with the species of Phyllopodium that are in the OG. A monophyletic Zaluzianskya was rejected by AU tests for all but 3-5\% of the trees. In the rare occasions when it was accepted by AU tests while monophyletic, Zaluzianskya s.s. (i.e., not including members of Reyemia or Phyllopodium) was sister to the other typical members of the Zaluzianskya clade and placed on a short branch. The monophyly of Phyllopodium s.l. was completely rejected by AU tests (max p-value $<0.001)$.

The strongly supported clade 2 of Zaluzianskya in Archibald et al. (2005) is now associated with several newly sampled accessions, including three Phyllopodium species plus an additional species of sect. Reyemia. This portion of the phylogeny includes four 
strongly supported clades: Z. peduncularis + Z. cohabitans + Z. elgonensis, Z. divaricata $+Z$. pusilla, sect. Reyemia, and Ph. mimetes + Ph. cf. cephalophorum (for the analyses that included them). The relationships among these clades varied somewhat or were unresolved, with the Reyemia clade and Ph. mimetes changing positions. Support for these alternate placements was often weak or lacking. More evidence is needed to determine basal relationships within clade 2 and to verify whether $P h$. mimetes and $P h$. cf. cephalophorum belong with this clade or elsewhere within Zaluzianskya.

Up to four other species of Phyllopodium were sampled for some analyses, and most analyses placed them in a clade with up to six species of Polycarena. The exception is the level 3 cpDNA analyses, which placed some or all of these Phyllopodium species in a polytomy with Polycarena and other OGs. Polycarena was strongly supported as monophyletic by all analyses but was nested within Phyllopodium by most. It was weakly to strongly inferred as sister to Ph. cuneifolium by ITS and concatenated analyses, and weakly inferred as sister to $P h$. rustii and Ph. dolomiticum by some cpDNA analyses. Other cpDNA analyses did not resolve relationships between the Polycarena clade and Phyllopodium.

In general, relationships among the remaining OGs are consistent with those found by Kornhall and colleagues (Kornhall, 2004; Kornhall and Bremer, 2004; Kornhall et al., 2001), and those studies should be referred to for more detailed discussion for many of those clades. The OG accessions that were sequenced by our research group do not have "GB" in their population ID (Fig. 2) and, for the most part, are placed with other species of their genera. One exception is Trieenea, which was not monophyletic in these trees. However, only our ITS sequence is available for T. taylorii, and while BI analyses 
strongly supported it as sister to Pseudoselago, MP analyses placed it unresolved in a position potentially closer to $T$. glutinosa GB. There was mixed support in our analyses for non-monophyly in Lyperia, Hebenstretia, and Selago, but only Phyllopodium in the outgroups was strongly and consistently resolved as polyphyletic. See Kornhall (2004, Ch. 4) in particular for relationships within Selago and close relatives. Overall, some differences arose among our analyses at different taxon-sampling levels, but this is unsurprising given the range from four to 48 accessions within the OG clades, and it does not result in any hard incongruences. In the OG, only the relationships among Manulea, Sutera, and Chaenostoma showed conflict between the ITS and cpDNA level 3 analyses. Regardless, these phylogenies are consistent with the decision of Kornhall and Bremer (2004) to divide Sutera s.l. into two genera (Sutera s.s. and Chaenostoma): cpDNA support a Manulea + Chaenostoma clade while ITS supports a Manulea + Sutera s.s. clade.

\subsection{Relationships in Zaluzianskya, with focus on clade 3, the Nycterinia +}

\section{Macrocalyx clade}

Clade 3 was resolved as monophyletic by all analyses except some MP-cpDNA analyses, which tentatively excluded $Z$. tropicalis from this clade. In the latter, $Z$. tropicalis was placed either in a polytomy with the rest of clade 3 and several other lineages or weakly as sister to sect. Reyemia. However, the differing MP-cpDNA resolutions had low clade support, and the cpDNA data for Z. tropicalis was relatively weak: it is the only accession of Zaluzianskya for which two of the four cpDNA regions failed to sequence. Concatenated analyses strongly support the monophyly of clade 3 and 
the placement of $Z$. tropicalis sister to the rest of the clade, while any conflicting placement by analyses of individual loci is not well supported (Fig. 3).

The only subclade in clade 3 that had strong support from all analyses was the clade of two populations of Z. mirabilis (i.e., the sole species included from sect. Macrocalyx). Many relationships were unresolved by all analyses. Most clades that did receive high support in some analyses were not strongly inferred by others (ITS in particular). There was one case of strong conflict between ITS and cpDNA. As also noted by Archibald et al. (2005), Z. mirabilis was very strongly inferred as nested in clade 3 by cpDNA and concatenated analyses, but was well supported as sister to a monophyletic sect. Nycterinia by MP-ITS analyses (JK = 72, level 1). Contrary to those results, the BIITS analyses do not resolve a monophyletic sect. Nycterinia, instead having no support for basal nodes within clade 3. The monophyly of sect. Nycterinia was neither supported nor rejected by AU tests.

When analyzed alone, ITS failed to resolve relationships in most of clade 3, only consistently inferring the clade of two populations of Z. mirabilis. Otherwise, the MP-ITS analyses had just two well-supported clades, a sect. Nyterinia clade, noted above, and a clade of four populations of Z. microsiphon (i.e., Z. microsiphon-3, A14, A15, A16; JK = 78, level 1). The latter is designated here Z. microsiphon-S, due to the relatively southern distribution of those populations compared to other sampled populations of $Z$. microsiphon. Within clade 3, the BI-ITS analyses only had strong support (PP>0.95) for the clade of $Z$. mirabilis populations. In contrast, the cpDNA and concatenated analyses strongly inferred a basal division of clade 3 (excluding Z. tropicalis) into two wellsupported clades (clades A and B; Fig. 3). They nested Z. mirabilis (of sect. Macrocalyx) 
in clade $3 \mathrm{~A}$ along with Z. microsiphon-S and two populations each of Z. angustifolia and Z. maritima. The cpDNA and concatenated analyses also strongly supported multiple subclades within clades A and B. Zaluzianskya capensis was strongly inferred as monophyletic, as was Z. glareosa, while the monophyly of many other species remained uncertain or contradicted by these analyses. Zaluzianskya microsiphon, in particular, was divided into multiple clades that did not group together on any of the trees. The monophyly of Z. microsiphon was rejected by AU tests (max p-value <0.001).

Clade 2 was discussed above in the context of generic relationships. Although many relationships in clade 1 are well supported, there are some conflicts between the ITS and cpDNA analyses due primarily to the unstable placement of several key taxa. In particular, Z. affinis-1 moved between two separated clades of Z. affinis, and Z. benthamiana-1 was sometimes placed within the $Z$. violacea clade. These differences are strongly supported by at least one analysis. Level 3 ITS analyses included one additional GenBank accession for both Z. gracilis and Z. villosa that were strongly inferred as members of the Z. villosa + Z. affinis + Z. gracilis clade.

\section{Discussion}

These analyses establish that the diversity within the Zaluzianskya clade is greater than previously known. A lack of monophyly for Zaluzianskya and Phyllopodium is revealed, with some species of the latter and all species of Reyemia now clearly shown as members of the Zaluzianskya clade. Two species of Zaluzianskya that are geographically isolated from the remainder of the genus were included in a molecular phylogeny for the 
first time and are confirmed as belonging in this genus. Finally, independent lineages are established among 21 populations of "Z. microsiphon," supporting the presence of multiple, rapidly evolving, species under this single name. Each of these results will be discussed in more detail below.

\subsection{Polyphyly of Phyllopodium and its partial inclusion with Reyemia in the Zaluzianskya clade}

Our phylogenetic analyses demonstrate that Zaluzianskya s.s. is not monophyletic, due to the embedding of species from at least two other genera. Despite evident differences in floral morphology, the transfer of Reyemia nemesioides and $R$. chasmanthiflora into Zaluzianskya now has strong phylogenetic support (Figs. 2, 3). Resupination, or developmental turning of a flower so that it is effectively upside down at maturity, is unique to Reyemia within tribe Limoselleae. These two species also add more highly branched inflorescences and presence of hairs in the corolla throat to the floral variation found in Zaluzianskya. See Manning and Goldblatt (2014), Archibald et al. (2005), and Hilliard (1994) for further discussion of the morphology and relationship of these two genera. The AU tests do not absolutely exclude the possibility of a monophyletic Zaluzianskya s.s., but they do fully reject a monophyletic Phyllopodium. All analyses demonstrate the need for detailed phylogenetic analyses of the latter genus. Only 4 to 7 of the 26 species of Phyllopodium were sampled, but our analyses segregate them into at least two, and up to four or five, separate groups. Available data place $P h$. cordatum, Ph. mimetes, and Ph. cf. cephalophorum in the Zaluzianskya clade, likely grouped with clades 2 and 3. The other species of Phyllopodium are placed as outgroups, 
either in a grade sister to Polycarena or at least partially unresolved within a larger clade containing Polycarena and other OGs.

We know of no broad phylogenetic studies of Phyllopodium. The studies of Kornhall and colleagues (Kornhall, 2004; Kornhall and Bremer, 2004; Kornhall et al., 2001) sampled up to four species of Phyllopodium (Ph. cuneifolium, Ph. dolomiticum, Ph. multifolium, Ph. cf. cephalophorum), up to five of Polycarena, and up to four of Zaluzianskya (Z. capensis, Z. glareosa, Z. gracilis, Z. villosa for ITS, Kornhall, 2004; Z. benthamiana, Z. katherinae, Z. glareosa for $n d h F$, Kornhall et al., 2001). The focus of those studies ranged from multiple tribes to subsets of genera in tribe Limoselleae. In all cases, most of Phyllopodium forms a clade with Polycarena, sometimes as sister genera and sometimes as a grade, as seen in the outgroup of the present study. Phyllopodium cf. cephalophorum is placed with Zaluzianskya, but that accession was misidentified in those papers as Z. minima, and so the odd placement was not noticeable. Once it was added to our analyses, with taxon sampling focused within Zaluzianskya, we noted its placement was not consistent with Z. minima and identified it as a member of subgenus Leiospermum in Phyllopodium based on examination of the original specimen. That subgenus includes four species. Our determination is that this specimen is probably $P h$. cephalophorum, but could be Ph. phyllopodioides. Hilliard (1994) recognized these as separate species, but also stated (p. 458) "The two species are very closely allied and it is difficult to formulate the distinctions between them."

A number of Hilliard's "principal characters" for the genera in the tribe are shared by Zaluzianskya and Phyllopodium (see Table 1 of Hilliard, 1994). In both genera the floral bract is adnate to the calyx, stem hairs are eglandular or stalked glandular, 
inflorescences are not cymes, posticous stamen filaments are decurrent to the corolla, stigmas are ligulate, and a lateral gland nectary is present. In the species for which chromosome counts are available, Zaluzianskya (nine species counted) and Phyllopodium (three species) also have the same number of chromosomes: $2 n=12$. Other species in the tribe for which counts are available range from $2 n=12$ to 28 . This combination of features is only additionally shared by three other genera of the 17 in the tribe (sensu Hilliard, 1994): Reyemia, Melanospermum, and Trieenea. However, Trieenea has chromosome counts of both 12 and 14, and counts are not available for Reyemia and Melanospermum. Both Melanospermum and Trieenea are placed separately from Zaluzianskya/Reyemia in our analyses (Fig. 2) and the tribal-level phylogenies of Kornhall et al. (2001). Some of these shared traits appear to be plesiomorphic (Kornhall et al., 2001). Regardless, a more thorough sampling of Phyllopodium for phylogenetic analyses is needed before synapomorphic characters for the Zaluzianskya clade can be determined and taxonomic changes made.

Morphologically, species of Zaluzianskya/Reyemia are distinguished from those of Phyllopodium by their toothed, plicate calyx whereas calyces of Phyllopodium are lobed halfway or nearly to the base. Calyx shape is diagnostic for multiple taxa in Hilliard's (1994) monograph. Anther number and placement for Phyllopodium is also different from Zaluzianskya, although the latter is variable for these traits. Most species of Phyllopodium have four, exserted anthers (two or three in selfing species). Zaluzianskya has two or four anthers, either all included or only the anticous pair exserted (although rarely the posticous pair is partly or entirely exserted as well); and both species of Reyemia have two anthers that are fully exserted. 
Hilliard (1994) divided Phyllopodium into two subgenera: Phyllopodium (22 species) and Leiospermum (four species; Table 1). The four OG-Phyllopodium species are from subgenus Phyllopodium subgroups 1A (Ph. cuneifolium, Ph. rustii) and 1B (Ph. dolomiticum, Ph. multifolium). The three sampled species that were placed with Zaluzianskya are from subgroup 2A (Ph. cordatum, Ph. mimetes) and subgenus Leiospermum (Ph. cf. cephalophorum). With three species from putatively divergent groups within Phyllopodium being strongly supported as nested within Zaluzianskya, it is likely that new combinations will be needed for those and other species from Phyllopodium. Taxonomic changes have not been made here, pending the collection of more evidence for each individual species whose movement is proposed. Groups 1 and 2 of Phyllopodium are mainly distinguished by Hilliard (1994) based on minute characteristics of the seed coat observed under an SEM, but she also discusses larger features for each group. For example, group 1 differs from 2 in having elongated racemes versus usually compact round heads. The latter is also characteristic of subgen. Leiospermum, and thus links all sampled Phyllopodium species that are placed in the Zaluzianskya clade. This is not a trait that would be expected to link outside species with Zaluzianskya, given that Zaluzianskya species have terminal spikes (or loose panicles, in the case of sect. Reyemia). Thus, the addition of both sect. Reyemia and these species of Phyllopodium to the Zaluzianskya clade significantly alters our understanding of the evolution of inflorescence architecture within this group. These species of Phyllopodium also differ from Zaluzianskya s.s. in having a beard of clavate hairs on the posticous lip of the corolla. This feature is found in a number of genera within the tribe, including Reyemia. It is not found in Zaluzianskya s.s., although some species have clavate hairs in 
a ring around the throat of the corolla (Hilliard, 1994). These corolla hairs have been hypothesized to influence pollinator interactions (Johnson et al., 2002).

We included 6 of the 17 species of Polycarena, with multiple members from both of the taxonomic groups proposed for this genus by Hilliard (1994). These species formed a very well-supported clade, but there is strong support for the nesting of this clade within a Phyllopodium clade by some of our analyses. Other analyses place Polycarena in a polytomy with some or all OG-Phyllopodium. Regardless, a close relationship between Polycarena and a subset of Phyllopodium is clear. This relationship is unsurprisingly consistent with Kornhall (2004), the source of our GenBank sequences, and has been noted since the naming of these genera (Bentham 1836). Some workers have suggested combining them (as noted by Hilliard, 1994, p. 71-72). However, Hilliard (1994) gives a number of features that may distinguish the two genera, including presence/absence of eglandular hairs and wings on seeds. Thorough phylogenetic investigations are needed to identify true synapomorphic characters and reconcile inferred genetic and morphological groups.

\subsection{Placement of disjuncts and relatives within Zaluzianskya}

While Zaluzianskya s.s. is found throughout most of South Africa and extends into several nearby countries, Phyllopodium is confined to the western and southern parts of South Africa, extending somewhat into Namibia. Zaluzianskya sect. Reyemia has an even narrower distribution, occurring only in a small area of west-central South Africa. Thus, these additions to the Zaluzianskya clade play no role in bridging the distributional gap seen between the rest of Zaluzianskya and the two disjunct species: Z. elgonensis 
from Tanzania and Uganda and Z. tropicalis from Zimbabwe and Mozambique.

Nonetheless, in the phylogeny, the latter two species were placed approximately where expected based on their taxonomic classification.

The addition of Z. elgonensis increased the number of sampled species from sect. Zaluzianskya subsect. Noctiflora to two of four (including also Z. peduncularis), allowing the first tests of the subsection's monophyly. These two do form a strongly supported subclade of clade 2, but only with the addition of Z. cohabitans of sect. Zaluzianskya subsect. Zaluzianskya (Fig. 3). The rest of subsect. Zaluzianskya is placed in clade 1. A sister relationship between Z. peduncularis and Z. cohabitans is strongly inferred by some analyses, while they form a polytomy with Z. elgonensis in others. Zaluzianskya cohabitans is distinct from other members of its subsection not only in its phylogenetic placement but also in its elliptic and typically entire petal lobes, compared to the notched petal lobes of most members of subsect. Zaluzianskya. Entire petal lobes characterize all members of clade 2, including the additions from Reyemia and Phyllopodium. This further supports the assessment by Archibald et al. (2005) that petal shape may be a useful character for infrageneric classification of Zaluzianskya.

Zaluzianskya tropicalis is generally resolved in clade 3 with the rest of section Nycterinia; the concatenated data strongly support a sister relationship between $Z$. tropicalis and the remainder of clade 3. Hilliard (1994) discusses Z. tropicalis as resembling Z. glareosa (two populations sampled here) and Z. distans (not sampled here). The phylogenies do not demonstrate a particular affinity between these taxa, but more data are needed. At a minimum, this disjunct species is strongly supported as a member of Zaluzianskya, but it seems to have diverged relatively early from the rest of its section. 


\subsection{The division of $Z$. microsiphon within the rapidly diversifying Nycterinia + Macrocalyx clade (clade 3)}

The clade in Zaluzianskya that remains least well known in terms of phylogenetic relationships is clade 3 (Fig. 3). It is strongly supported by all analyses as a monophyletic group, with the unlikely but possible exclusion of Z. tropicalis. Close genetic ties between the 15 sampled species imply rapid diversification. In addition to a partial lack of resolution, there is some conflict between the ITS and cpDNA trees. MP-ITS analyses inferred a monophyletic sect. Nycterinia while the other analyses nested Z. mirabilis within sect. Nycterinia or were not informative. Notably, BI-ITS analyses were in the latter group, adding long-branch attraction as a possible explanation for the proposed conflict. This is consistent with the relatively long branch to Z. mirabilis. See Archibald et al. (2005) for further discussion of the potential inclusion of Z. mirabilis among species from sect. Nycterinia. Three species from sect. Nycterinia were added to this study but not available to Archibald et al. (2005): Z. spathacea, Z. schmitziae, and the disjunct Z. tropicalis. Consistent with their classification, they were all placed in clade 3.

A previously-noted phylogenetic division of the day-flowering Z. microsiphon (Archibald et al., 2005) is confirmed by these analyses with much greater population sampling. Concatenated and cpDNA analyses decisively separate Z. microsiphon, with four populations, designated as Z. microsiphon-S, nested in one well-supported subclade (3A) and the remainder scattered in the other (subclade 3B). Zaluzianskya microsiphon-S is also the only group in sect. Nycterinia that is strongly inferred both by some ITS and cpDNA analyses. The populations of Z. microsiphon-S are separated by a minimum of 85 
$\mathrm{km}$ from the nearest sampled population of Z. microsiphon from subclade 3B. However, additional exploration of the intervening area is needed to check for other populations. There is weak to strong support for further subdivision of Z. microsiphon within clade 3B in cpDNA and concatenated trees, with populations grouping with members of other species. As many as six independent lineages of Z. microsiphon are strongly supported by one or more analysis, despite lack of resolution for many nodes in clade 3. Given the uncertain relationships within this clade, it is unsurprising that the exact pattern of evolution for these Z. microsiphon lineages is unclear. It is clear that the evolution of these plants has been more complex than recognized by previous workers (e.g., Hilliard, 1994). The relative importance of convergent evolution vs. hybridization in these divisions remains undetermined. If further data confirm the division into six or more lineages, it seems unlikely that each of those lineages was artificially separated on the tree due to the confounding effects of hybridization on phylogenetic analyses. Although Z. microsiphon is locally sympatric with multiple members of sect. Nycterinia (pers. obs.), the rest of the section is night flowering. Hybridization has been confirmed at one site between Z. microsiphon and Z. natalensis, demonstrating that the difference in flower-opening time is not an absolute barrier to gene flow in this case. However, it is at least a partial barrier, and it combines with other forms of reproductive isolation, such as differences in floral orientation that lead to differential pollinator attraction (Archibald et al., 2004; Campbell et al., 2016).

An important factor in the evolution of these lineages appears to be longproboscid flies. Prosoeca ganglbaueri (Nemestrinidae) is the main pollinator of most populations of Z. microsiphon, and Z. microsiphon is the primary (although not the only) 
food source for the flies (Anderson and Johnson, 2008; Johnson et al., 2002). Anderson and Johnson (2008) found trait covariation for corolla tube length and proboscid length, indicating coevolution or possibly sequential trait evolution. Variation in tube lengths within a population was relatively low, but average lengths across populations ranged widely from 19.4 to $54.6 \mathrm{~mm}(\mathrm{~N}=20-59)$. Most of the populations studied by Anderson and Johnson (2008) are included here, allowing us to add a preliminary phylogenetic framework to their comparison. Many of the well-supported clades of Z. microsiphon encompass a variety of tube-lengths. For example, average tube lengths even just across populations of Z. microsiphon-S range from ca. 33 to $52 \mathrm{~mm}$. This suggests that the rate of tube-length evolution is quite fast, with repeated changes within separate lineages of $Z$. microsiphon. However, again, hybridization may also be at work. According to Hilliard's (1994) monograph and consistent with our measurements, tube lengths of all other species sampled in clade 3 range from 17 to $60 \mathrm{~mm}$. Some of this variation may be moving into any given population of Z. microsiphon through inter-species gene flow. Again using Z. microsiphon-S as an example, it is sister to a grade of populations of $Z$. angustifolia. The range of variation given for that species by Hilliard (1994) is 17-50 $\mathrm{mm}$, which overlaps with that of Z. microsiphon-S. This gives two, non-mutuallyexclusive hypotheses for the evolution of tube length variation in Z. microsiphon. One is that pollinator-mediated selection favoring particular mutations/recombinations is driving very rapid tube length evolution within populations. The other is that hybridization with night-flowering species has increased tube length variation in populations of $Z$. microsiphon, and this may have accelerated rates of pollinator-mediated floral evolution in this species. The correlation between tube and proboscid lengths found by Anderson 
and Johnson (2008) is indicative of a role for coevolution between long-proboscid flies and Z. microsiphon. However, the phylogenetic data for Zaluzianskya presented here paint a more complex picture of possible convergent evolution of day-opening flowers pollinated by long-proboscid flies.

While the cpDNA data were more informative for clade 3 than ITS, clearly more characters are needed to attempt robust inference of relationships among these species and populations. Given the conflict seen between loci and at least some potential for hybridization, a comparison is also needed with other data sources. We have conducted ISSR analyses within this clade (Archibald J.K., Anderson B., Johnson S.D., unpub.) and found that even such hypervariable molecular markers struggle in resolving these relationships. A phylogenomic approach may be required to provide an evolutionary framework for this clade (Andrews et al., 2016; Mort et al., 2015; Wessinger et al., 2016).

\section{Conclusions and future directions}

This work demonstrates the lack of monophyly of Zaluzianskya and Phyllopodium and the need for a phylogeny across the latter. The inclusion of Reyemia and some species of Phyllopodium expands the known morphological diversity within the Zaluzianskya clade, particularly in floral and inflorescence characters. Such traits were already known to be variable in Zaluzianskya, suggesting potential roles for pollinator interactions in the evolution of these species (Johnson, 2006). Such a role is supported by study thus far of the interactions between Z. microsiphon and its pollinating longproboscid fly (Anderson and Johnson, 2008), although the role of hybridization requires further study. These results establish the placement of disjuncts within Zaluzianskya and 
the broad phylogenetic division of $Z$. microsiphon, but many questions remain. This is particularly notable within clade 3 , with many relationships being unresolved. In addition to Z. microsiphon, other species complexes have been identified by this and previous work (Archibald et al., 2005), including the Z. villosa complex (Z. villosa, Z. affinis, and Z. gracilis) and the potential progenitor-derivative pair of $Z$. pusilla and Z. divaricata. We sampled additional populations from each, further substantiating the complicated nature of their evolution. Continued population sampling and more data are needed to better elucidate the patterns and processes of evolution within the Zaluzianskya clade.

\section{Acknowledgements}

This research was supported by the Biodiversity Institute and the Department of Ecology and Evolutionary Biology at the University of Kansas (KU), National Science Foundation (NSF) Research Experiences for Undergraduates grant DBI-0353911 in support of JC at KU, and NSF grant DEB-0089640 to MEM. Field and collecting assistance was provided by N. Barker, J. Beyers, P. Burgoyne, T. Edwards, N. Levsen, C. Peter, C. Randle, K. Roux, K. Steiner, F. Smith, G. Smith, D. Snijman, and A. Wolfe. An herbarium specimen of Phyllopodium cf. cephalophorum (B. Bremer \& K. Bremer 3542) was kindly made available for identification from UPS, and K provided DNA extracts for three species.

The authors also thank D. Crawford, C. Freeman, P. Kornhall, and anonymous reviewers for helpful discussion. 


\section{Literature cited}

Anderson, B., Johnson, S.D., 2006. The effects of floral mimics and models on each others' fitness. Proc. R. Soc. B-Biol. Sci. 273, 969-974.

Anderson, B., Johnson, S.D., 2008. The geographical mosaic of coevolution in a plantpollinator mutualism. Evolution 62, 220-225.

Anderson, B., Johnson, S.D., Carbutt, C., 2005. Exploitation of a specialized mutualism by a deceptive orchid. American Journal of Botany 92, 1342-1349.

Andrews, K.R., Good, J.M., Miller, M.R., Luikart, G., Hohenlohe, P.A. 2016. Harnessing the power of RADseq for ecological and evolutionary genomics. Nature Reviews Genetics 17, 81-92.

Archibald, J.K., Mort, M.E., Wolfe, A.D., 2005. Phylogenetic relationships within Zaluzianskya (Scrophulariaceae s.s., tribe Manuleeae): classification based on DNA sequences from multiple genomes and implications for character evolution and biogeography. Systematic Botany 30, 196-215.

Archibald, J.K., Wolfe, A.D., Johnson, S.D., 2004. Hybridization and gene flow between a day- and night-flowering species of Zaluzianskya (Scrophulariaceae s.s., tribe Manuleeae). American Journal of Botany 91, 1333-1344.

Baldwin, B.G., Sanderson, M.J., Porter, J.M., Wojciechowski, M.F., Campbell, C.S., Donoghue, M.J., 1995. The ITS region of nuclear ribosomal DNA: a valuable source of evidence on angiosperm phylogeny. Annals of the Missouri Botanical Garden 82, 247277.

Bentham, G., 1836. Synopsis of the Buchnereae, a tribe of the Scrophulariaceae. Companion Bot. Mag. 1, 356-384.

Campbell, D.R., Jürgens, A., Johnson, S.D., 2016. Reproductive isolation between Zaluzianskya species: the influence of volatiles and flower orientation on hawkmoth foraging choices. New Phytologist 210, 333-342.

Cowling, R.M., Proches, S., Partridge, T.C., 2009. Explaining the uniqueness of the Cape flora: incorporating geomorphic evolution as a factor for explaining its diversification. Molecular Phylogenetics and Evolution 51, 64-74.

Demesure, B., Sodzi, N., Petit, R.J., 1995. A set of universal primers for amplification of polymorphic noncoding regions of mitochondrial and chloroplast DNA in plants. Molecular Ecology 4, 129-131. 
Downie, S.R., Katz-Downie, D.S., Watson, M.F., 2000. A phylogeny of the flowering plant family Apiaceae based on chloroplast DNA rpl16 and rpoC1 intron sequences: towards a suprageneric classification of subfamily Apioideae. American Journal of Botany 87, 273-292.

Doyle, J.J., Doyle, J.L., 1987. A rapid DNA isolation procedure for small quantities of fresh leaf tissue. Phytochemistry Bulletin 19, 11-15.

Hilliard, O.M., 1994. The Manuleae. A Tribe of Scrophulariaceae. Edinburgh University Press, Edinburgh, UK.

Hilliard, O.M., 1999. The Tribe Selagineae (Scrophulariaceae). Kew Publishing, Royal Botanic Garden, Edinburgh.

Johnson, S.D., 2006. Pollinator-driven speciation in plants. In: Harder, L.D., Barrett, S.C.H. (Eds.), The Ecology and Evolution of Flowers. Oxford University Press, Oxford, pp. 295-310.

Johnson, S.D., Edwards, T.J., Carbutt, C., Potgieter, C., 2002. Specialization for hawkmoth and long-proboscid fly pollination in Zaluzianskya section Nycterinia (Scrophulariaceae). Botanical Journal of the Linnean Society 138, 17-27.

Kellogg, E.A., Appels, R., Mason-Gamer, R.J., 1996. When genes tell different stories: the diploid genera of Triticeae (Gramineae). Systematic Botany 21, 321-347.

Kornhall, P., 2004. Phylogenetic Studies in the Lamiales with Special Focus on Scrophulariaceae and Stilbaceae. Ph.D. Science and Technology. Uppsala University.

Kornhall, P., Bremer, B., 2004. New circumscription of the tribe Limoselleae (Scrophulariaceae) that includes the taxa of the tribe Manuleeae. Botanical Journal of the Linnean Society 146, 453-467.

Kornhall, P., Heidari, N., Bremer, B., 2001. Selagineae and Manuleeae, two tribes or one? Phylogenetic studies in the Scrophulariaceae. Plant Systematics and Evolution 228, 199-218.

Maddison, D.R., 1991. The discovery and importance of multiple islands of mostparsimonious trees. Systematic Zoology 40, 315-328.

Manning, J.C., Goldblatt, P., 2010. Scrophulariaceae. Two new species of Limoselleae from western South Africa: Trieenia occulta and Zaluzianskya regalis. Bothalia 40, 8490.

Manning, J.C., Goldblatt, P., 2014. Reyemia included in Zaluzianskya (Scrophulariaceae: Limoselleae), with the new combination Zaluzianskya chasmanthiflora (Hilliard) J.C. Manning \& Goldblatt. In: Goldblatt, P., Manning, J.C. (Eds.), Nomenclatural Adjustments in African Plants 1. Bothalia 44: 9 pp. 
Mason-Gamer, R.J., Kellogg, E.A., 1996. Testing for phylogenetic conflict among molecular data sets in the tribe Triticeae (Gramineae). Systematic Biology 45, 524-545.

McDade, L.A., 1992. Hybrids and phylogenetic systematics II. The impact of hybrids on cladistic analysis. Evolution 46, 1329-1346.

Mort, M.E., Archibald, J.K., Randle, C.P., Levsen, N.D., O'Leary, T.R., Topalov, K., Wiegand, C.M., Crawford, D.J., 2007. Inferring phylogeny at low taxonomic levels: utility of rapidly evolving cpDNA and nuclear ITS loci. American Journal of Botany 94, 173-183.

Mort, M.E., Crawford, D.J., Kelly, J.K., Santos-Guerra, A., de Sequeira, M.M., Moura, M., Caujape-Castells, J. 2015. Multiplexed-shotgun-genotyping data resolve phylogeny within a very recently derived insular lineage. American Journal of Botany 102, 634-641.

Mort, M.E., Soltis, D.E., Soltis, P.S., Francisco-Ortega, J., Santos-Guerra, A., 2001. Phylogenetic relationships and evolution of Crassulaceae inferred from $\mathrm{matK}$ sequence data. American Journal of Botany 88, 76-91.

Müller, K., 2005. SeqState - primer design and sequence statistics for phylogenetic DNA data sets. Applied Bioinformatics 4, 65-69.

Nylander, J.A.A., Wilgenbusch, J.C., Warren, D.L., Swofford, D.L., 2008. AWTY (are we there yet?): a system for graphical exploration of MCMC convergence in Bayesian phylogenetics. Bioinformatics 24, 581-583.

Oxelman, B., Liden, M., Berglund, D., 1997. Chloroplast rps16 intron phylogeny of the tribe Sileneae (Caryophyllaceae). Plant Systematics and Evolution 206, 393-410.

Posada, D., 2008. jModelTest: phylogenetic model averaging. Molecular Biology and Evolution 25, 1253-1256.

Rambaut, A., 2002. Se-Al sequence alignment editor, version 2.0a11. Oxford: Department of Zoology, University of Oxford.

Rambaut, A., Drummond, A.J., 2007. Tracer. <http://beast.bio.ed.ac.uk/Tracer>.

Ronquist, F., Teslenko, M., van der Mark, P., Ayres, D.L., Darling, A., Höhna, S., Larget, B., Liu, L., Suchard, M.A., Huelsenbeck, J.P., 2012. MrBayes 3.2: Efficient Bayesian phylogenetic inference and model choice across a large model space. Systematic Biology $61,539-542$.

Shaw, J., Lickey, E.B., Beck, J.T., Farmer, S.B., Liu, W.S., Miller, J., Siripun, K.C., Winder, C.T., Schilling, E.E., Small, R.L., 2005. The tortoise and the hare II: relative utility of 21 noncoding chloroplast DNA sequences for phylogenetic analysis. American Journal of Botany 92, 142-166. 
Shaw, J., Lickey, E.B., Schilling, E.E., Small, R.L., 2007. Comparison of whole chloroplast genome sequences to choose noncoding regions for phylogenetic studies in angiosperms: the tortoise and the hare III. American Journal of Botany 94, 275-288.

Shimodaira, H., 2002. An approximately unbiased test of phylogenetic tree selection. Systematic Biology 51, 492-508.

Simmons, M.P., 2004. Independence of alignment and tree search. Molecular Phylogenetics and Evolution 31, 874-879.

Simmons, M.P., Ochoterena, H., 2000. Gaps as characters in sequence-based phylogenetic analyses. Systematic Biology 49, 369-381.

Soltis, D.E., Mavrodiev, E.V., Doyle, J.J., Rauscher, J., Soltis, P.S., 2008. ITS and ETS sequence data and phylogeny reconstruction in allopolyploids and hybrids. Systematic Botany 33, 7-20.

Soltis, D.E., Soltis, P.S., 1997. Phylogenetic relationships in Saxifragaceae sensu lato: a comparison of topologies based on $18 \mathrm{~S}$ rDNA and $r b c L$ sequences. American Journal of Botany 84, 504-522.

Swofford, D.L., 2003. PAUP*. Phylogenetic Analysis Using Parsimony (*and Other Methods). Version 4. Sinauer, Sunderland, Massachusetts.

Taberlet, P., Gielly, L., Pautou, G., Bouvet, J., 1991. Universal primers for amplification of three non-coding regions of chloroplast DNA. Plant Mol.Biol. 17, 1105-1109.

Wen, J., Zimmer, E.A., 1996. Phylogeny and biogeography of Panax L. (the ginseng genus, Araliaceae): inferences from ITS sequences of nuclear ribosomal DNA. Molecular Phylogenetics and Evolution 6, 167-177.

Wessinger, C.A., Freeman, C.C., Mort, M.E., Rausher, M.D., Hileman, L.C. 2016. Multiplexed shotgun genotyping resolves species relationships within the North American genus Penstemon. American Journal of Botany 103, 912-922.

Wilgenbusch, J.C., Warren, D.L., Swofford, D.L., 2004. AWTY: A System for Graphical Exploration of MCMC Convergence in Bayesian Phylogenetic Inference. <http:// ceb.csit.fsu.edu/awty>.

Zwickl, D.J., 2006. Genetic algorithm approaches for the phylogenetic analysis of large biological sequence datasets under the maximum likelihood criterion. www.bio.utexas.edu/faculty/antisense/garli/Garli.html. Ph.D. dissertation The University of Texas. 
Fig. 1. Photographs illustrating a sample of the morphological diversity of Zaluzianskya. (A) Z. pulvinata, sect. Nycterinia. (B) Z. microsiphon, sect. Nycterinia. (C) Z. pusilla, sect. Holomeria. (D) Z. affinis, sect. Zaluzianskya subsect. Zaluzianskya.

Fig. 2. Phylogeny across major clades of tribe Limoselleae, with focus on the Zaluzianskya clade, as inferred from level 3 (see Table 2) Bayesian and maximum parsimony concatenated analyses. Node support for concatenated, ITS, and trnL-trnF analyses is given in that order, with jackknife values (JK) above the branch and posterior probabilities $(\mathrm{PP})$ below. $*=\mathrm{JK}>70, \mathrm{PP}>0.95,-=$ node with lower support or unresolved by that analysis, $\mathrm{x}=$ analysis strongly supports an alternate resolution (also indicated by black dashed branches $),{ }^{\wedge}=$ clade not relevant to the analysis due to unsampled accessions for that DNA region. The latter are also indicated by gray dashed branches and the DNA region available is noted after the accession name. Population ID is given to the right of taxon names, except for species with only one sampled population. Bars to the right of taxon names indicate major groups. Phyllopodium is in blue, former Reyemia in green, and Zaluzianskya in yellow.

Fig. 3. Phylogeny of the Zaluzianskya clade as inferred from level 1 (see Table 2) Bayesian and maximum parsimony concatenated analyses. Node support for concatenated, ITS, and cpDNA (trnL-trnF, rpl16, rps16, and trnS-trnfM) analyses is given in that order, with jackknife values (JK) above the branch and posterior 
probabilities $(\mathrm{PP})$ below. $*=\mathrm{JK}>70, \mathrm{PP}>0.95,-=$ node with lower support or unresolved by that analysis, $\mathrm{x}=$ analysis strongly supports an alternate resolution (also indicated by black dashed branches). Gray dashed branches show the placement of individuals of Phyllopodium that were not included in level 1 analyses, but were sampled for levels 2 and/or 3. Population ID is given to the right of taxon names, except for species with only one sampled population. Bars to the right of taxon names note sectional affiliation $(\mathrm{N}$ : Nycterinia, M: Macrocalyx, Z: Zaluzianskya, R: Reyemia, H: Holomeria). Phyllopodium is in blue, former Reyemia in green, and Z. microsiphon in yellow. 
Table 1. Taxonomic divisions within Zaluzianskya and Phyllopodium, sampling within each subgroup, and phylogenetic placement of sampled species of Phyllopodium (i.e., with the outgroup or with the Zaluzianskya clade).

\begin{tabular}{|c|c|c|c|c|c|}
\hline Genus & Infrageneric groups & & & $\begin{array}{l}\text { No. sampled } \\
\text { species }\end{array}$ & $\begin{array}{l}\text { No. } \\
\text { species }\end{array}$ \\
\hline Zaluzianskya & Section Holomeria & & & 3 & 10 \\
\hline & Section Macrocalyx & & & 1 & 5 \\
\hline & Section Nycterinia & & & 14 & 20 \\
\hline & Section Reyemia & & & 2 & 2 \\
\hline & Section Zaluzianskya & subsect. $I$ & tiflora & 2 & 4 \\
\hline & & subsect. 2 & uzianskya & 7 & 17 \\
\hline Phyllopodium & Subgenus Leiospermum & & & $1-Z a l$ & 4 \\
\hline & Subgenus Phyllopodium & Group 1 & Subgroup 1A & $2-\mathrm{OG}$ & 4 \\
\hline & & & Subgroup 1B & $2-\mathrm{OG}$ & 3 \\
\hline & & & Subgroup 1C & 0 & 5 \\
\hline & & Group 2 & Subgroup 2A & $2-Z a l$ & 3 \\
\hline & & & Subgroup 2B & 0 & 5 \\
\hline & & "Anomal & species" & 0 & 2 \\
\hline
\end{tabular}


Table 2. Characteristics of final concatenated DNA sequence datasets and resulting maximum parsimony (MP) and Bayesian inference (BI) analyses of the Zaluzianskya clade (Zal) and outgroups (OG). The Zal clade includes former members of Reyemia (now Zaluzianskya sect. Reyemia) and several of the sampled species of Phyllopodium. Ranges for numbers of accessions reflect minor differences in sampling between concatenated, ITS, and cpDNA analyses.

\begin{tabular}{|c|c|c|c|}
\hline & $\begin{array}{l}\text { Level 1: Focused } \\
\text { analysis of } Z a l\end{array}$ & $\begin{array}{l}\text { Level 2: } \mathrm{Zal} \text { with } \\
\text { broader OG sampling } \\
\text { but more missing data }\end{array}$ & $\begin{array}{l}\text { Level 3: Zal and } \\
\text { representatives across } \\
\text { Tribe Limoselleae } \\
\text { with fewer loci }\end{array}$ \\
\hline Data & $\begin{array}{l}\text { ITS, trnL-F, rpl16, } \\
\text { rps } 16, t r n S-f M\end{array}$ & $\begin{array}{l}\text { ITS, } \operatorname{trnL}-F, r p l 16 \text {, } \\
\text { rps } 16, t r n S-f M\end{array}$ & ITS, $\operatorname{trn} L-F$ \\
\hline No. pops. ( $\mathrm{Zal}, \mathrm{OG})$ & $81(77,4)$ & $90-91(78,12-13)$ & $\begin{array}{l}125-130(80-83,45- \\
50)\end{array}$ \\
\hline No. species $(\mathrm{Zal}, \mathrm{OG})$ & $34(30,4)$ & $43-44(31,12-13)$ & $76-80(32,44-48)$ \\
\hline No. genera & 4 & $9-10$ & $22-23$ \\
\hline No. characters (nuc., indel) & $4934(4807,127)$ & $4934(4807,127)$ & 1759 (nuc. only) \\
\hline $\begin{array}{l}\text { No. potentially parsimony } \\
\text { informative chars. } \\
\text { MP analyses }\end{array}$ & 508 (423 in Zal) & 764 (427 in Zal) & $476(163$ in $\mathrm{Zal})$ \\
\hline $\begin{array}{l}\text { No., length of most } \\
\text { parsimonious trees }\end{array}$ & 24,1084 & 108,1694 & 2533,1451 \\
\hline $\mathrm{CI}$ & 0.668 & 0.667 & 0.489 \\
\hline RI & 0.917 & 0.897 & 0.856 \\
\hline $\mathrm{RC}$ & 0.612 & 0.598 & 0.418 \\
\hline \multicolumn{4}{|l|}{ BI analyses } \\
\hline Best-fit model & TIM1+G & TIM1+I+G & TIM1+I+G \\
\hline No. generations & $1,215,750,000$ & $1,215,750,000$ & $662,400,000$ \\
\hline
\end{tabular}


Appendix. Populations sampled for phylogenetic analyses of Zaluzianskya F.W. Schmidt and related genera. Geographic location and collection number are given. GenBank accession numbers for sequences of nuclear (ITS) and chloroplast (trnL-trnF, rpl16, rps 16, and $\operatorname{trnS}$-trnfM) DNA regions are listed in that order. [NOTE: GenBank numbers for new sequences will be added later].

\begin{tabular}{|c|c|c|c|c|c|}
\hline Section/Subgroup $^{\mathrm{a}}$ & Species & $\begin{array}{l}\text { Pop. } \\
\text { no. }\end{array}$ & Location & $\begin{array}{l}\text { Voucher (Herbarium); Indiv. } \\
\text { sequenced }\end{array}$ & $\begin{array}{l}\text { GenBank nos. (ITS, trnL-trnF, rpl16, rps16, } \\
\text { trnS-trnfM) }\end{array}$ \\
\hline Holomeria & Z. benthamiana Walp. & 1 & $\begin{array}{l}29.6651 \mathrm{~S} \\
17.9985 \mathrm{E}\end{array}$ & J.K. Archibald 12 (OS); 1 & $\begin{array}{l}\text { AY712572, AY712650, AY712611, XX, } \\
\text { XX }\end{array}$ \\
\hline Holomeria & Z. benthamiana & 2 & $\begin{array}{l}32.8833 \mathrm{~S} \\
19.7112 \mathrm{E}\end{array}$ & J.K. Archibald 72 (OS); 1 & $\mathbf{X X}, \mathbf{X X}, \mathbf{X X}, \mathbf{X X}, \mathbf{X X}$ \\
\hline Holomeria & Z. benthamiana & 3 & $\begin{array}{l}29.6847 \mathrm{~S} \\
17.9017 \mathrm{E}\end{array}$ & J.K. Archibald 10 (OS); 1 & $\mathbf{X X}, \mathbf{X X}, \mathbf{X X}, \mathbf{X X}, \mathbf{X X}$ \\
\hline Holomeria & $\begin{array}{l}\text { Z. divaricata (Thunb.) } \\
\text { Walp. }\end{array}$ & 1 & $\begin{array}{l}34.0553 \mathrm{~S} \\
19.1652 \mathrm{E}\end{array}$ & J.K. Archibald 31 (OS); a & $\begin{array}{l}\text { AY712569, AY712647, AY712608, XX, } \\
\text { XX }\end{array}$ \\
\hline Holomeria & Z. divaricata & 2 & $\begin{array}{l}34.0553 \mathrm{~S} \\
20.4475 \mathrm{E}\end{array}$ & $\begin{array}{l}\text { J.K. Archibald \& M.E. Mort } \\
200 \text { (KANU) ; } 1\end{array}$ & $\mathbf{X X}, \mathbf{X X}, \mathbf{X X}, \mathbf{X X}, \mathbf{X X}$ \\
\hline Holomeria & Z. pusilla (Benth.) Walp. & 1 & $\begin{array}{l}32.8805 \mathrm{~S} \\
19.6640 \mathrm{E}\end{array}$ & J.K. Archibald 76 (OS); 2 & $\begin{array}{l}\text { AY712570, AY712648, AY712609, XX, } \\
\mathbf{X X}\end{array}$ \\
\hline Holomeria & Z. pusilla & 2 & $\begin{array}{l}31.3798 \mathrm{~S} \\
19.0940 \mathrm{E}\end{array}$ & J.K. Archibald 26.1 (OS); 1 & $\begin{array}{l}\text { AY712571, AY712649, AY712610, XX, } \\
\mathbf{X X}\end{array}$ \\
\hline Macrocalyx & Z. mirabilis Hilliard & 1 & $\begin{array}{l}32.5504 \mathrm{~S} \\
20.2626 \mathrm{E}\end{array}$ & J.K. Archibald 68 (OS); 1 & $\begin{array}{l}\text { AY712559, AY712637, AY712598, XX, } \\
\text { XX }\end{array}$ \\
\hline Macrocalyx & Z. mirabilis & 2 & $\begin{array}{l}32.2058 \mathrm{~S} \\
20.1771 \mathrm{E}\end{array}$ & A.D. Wolfe 956 (OS); 1 & $\mathbf{X X}, \mathbf{X X}, \mathbf{X X}, \mathbf{X X}, \mathbf{X X}$ \\
\hline Nycterinia & $\begin{array}{l}\text { Z. angustifolia Hilliard \& } \\
\text { B.L. Burtt }\end{array}$ & 1 & $\begin{array}{l}31.0307 \mathrm{~S} \\
30.1735 \mathrm{E}\end{array}$ & J.K. Archibald 119 (OS); 1 & $\begin{array}{l}\text { AY712550, AY712628, AY712589, XX, } \\
\text { XX }\end{array}$ \\
\hline Nycterinia & Z. angustifolia & 2 & $\begin{array}{l}\text { ca. } 32.6 \mathrm{~S} \\
27.0 \mathrm{E}\end{array}$ & C. Peter 9xi00 s.n. (NU); 1 & $\begin{array}{l}\text { AY712551, AY712629, AY712590, XX, } \\
\text { XX }\end{array}$ \\
\hline Nycterinia & Z. capensis (L.) Walp. & 1 & $\begin{array}{l}34.8205 \mathrm{~S} \\
20.0126 \mathrm{E}\end{array}$ & J.K. Archibald 2 (OS); 1 & $\begin{array}{l}\text { AY712555, AY712633, AY712594, XX, } \\
\text { XX }\end{array}$ \\
\hline Nycterinia & Z. capensis & 2 & $\begin{array}{l}34.4758 \mathrm{~S} \\
20.5092 \mathrm{E}\end{array}$ & J.K. Archibald 5 (OS); 1 & $\mathbf{X X}, \mathbf{X X}, \mathbf{X X}, \mathbf{X X}, \mathbf{X X}$ \\
\hline Nycterinia & Z. capensis & 3 & $\begin{array}{l}34.1040 \mathrm{~S} \\
18.4310 \mathrm{E}\end{array}$ & $\begin{array}{l}\text { J.K. Archibald \& A.D. Wolfe } \\
9 \text { (OS); a }\end{array}$ & $\mathbf{X X}, \mathbf{X X}, \mathbf{X X}, \mathbf{X X}, \mathbf{X X}$ \\
\hline Nycterinia & $\begin{array}{l}\text { Z. elongata Hilliard \& B.L. } \\
\text { Burtt }\end{array}$ & 1 & $\begin{array}{l}30.7270 \mathrm{~S} \\
30.2969 \mathrm{E}\end{array}$ & $\begin{array}{l}\text { J.K. Archibald \& A.D. Wolfe } \\
8(\mathrm{OS}) ; \mathrm{a}\end{array}$ & $\begin{array}{l}\text { AY712552, AY712630, AY712591, XX, } \\
\text { XX }\end{array}$ \\
\hline Nycterinia & Z. elongata & 2 & $25.2361 \mathrm{~S}$ & M.E. Mort, C.P. Randle, \& & $\mathbf{X X}, \mathbf{X X}, \mathbf{X X}, \mathbf{X X}, \mathbf{X X}$ \\
\hline
\end{tabular}




\begin{tabular}{|c|c|c|c|c|c|}
\hline & & & $30.4892 \mathrm{E}$ & $\begin{array}{l}\text { J.K. Archibald } 05.004 \\
\text { (KANU); } 1\end{array}$ & \\
\hline Nycterinia & Z. elongata & 3 & $\begin{array}{l}29.4629 \mathrm{~S} \\
29.9628 \mathrm{E}\end{array}$ & J.K. Archibald 80 (OS); a & $\mathbf{X X}, \mathbf{X X}, \mathbf{X X}, \mathbf{X X}, \mathbf{X X}$ \\
\hline Nycterinia & $\begin{array}{l}\text { Z. glareosa Hilliard \& B.L. } \\
\text { Burtt }\end{array}$ & 1 & $\begin{array}{l}29.7355 \mathrm{~S} \\
29.1880 \mathrm{E}\end{array}$ & J.K. Archibald 90 (OS); a & $\begin{array}{l}\text { AY712556, AY712634, AY712595, XX, } \\
\text { XX }\end{array}$ \\
\hline Nycterinia & Z. glareosa & 2 & $\begin{array}{l}28.7458 \mathrm{~S} \\
28.8867 \mathrm{E}\end{array}$ & J.K. Archibald 104 (OS); a & $\mathbf{X X}, \mathbf{X X}, \mathbf{X X}, \mathbf{X X}, \mathbf{X X}$ \\
\hline Nycterinia & Z. katharinae Hiern & 1 & $\begin{array}{l}\text { Kirstenbosc } \\
\text { h Garden }\end{array}$ & A.D. Wolfe 729 (OS); 1 & $\begin{array}{l}\text { AY712557, AY712635, AY712596, XX, } \\
\text { XX }\end{array}$ \\
\hline Nycterinia & Z. maritima (L.f.) Walp. & 1 & $\begin{array}{l}34.0464 \mathrm{~S} \\
22.8417 \mathrm{E}\end{array}$ & J.K. Archibald 8 (OS); 1 & $\begin{array}{l}\text { AY712554, AY712632, AY712593, XX, } \\
\text { XX }\end{array}$ \\
\hline Nycterinia & Z. maritima & 2 & $\begin{array}{l}33.7449 \mathrm{~S} \\
26.5598 \mathrm{E}\end{array}$ & $\begin{array}{l}\text { J.K. Archibald \& M.E. Mort } \\
232 \text { (KANU); } 1\end{array}$ & $\mathbf{X X}, \mathbf{X X}, \mathbf{X X}, \mathbf{X X}, \mathbf{X X}$ \\
\hline Nycterinia & $\begin{array}{l}\text { Z. microsiphon (O. Kuntze) } \\
\text { K. Schum. }\end{array}$ & 1 & $\begin{array}{l}28.6860 \mathrm{~S} \\
28.9001 \mathrm{E}\end{array}$ & $\begin{array}{l}\text { S.D. Johnson 19ii00 s.n. } \\
\text { (NU); } 1\end{array}$ & $\begin{array}{l}\text { AY712545, AY712623, AY712584, XX, } \\
\text { XX }\end{array}$ \\
\hline Nycterinia & Z. microsiphon & 2 & $\begin{array}{l}29.5976 \mathrm{~S} \\
29.3119 \mathrm{E}\end{array}$ & J.K. Archibald 98 (OS); a & $\begin{array}{l}\text { AY712546, AY712624, AY712585, XX, } \\
\text { XX }\end{array}$ \\
\hline Nycterinia & Z. microsiphon & 3 & $\begin{array}{l}\text { ca. } 30.7 \mathrm{~S} \\
28.1 \mathrm{E}\end{array}$ & $\begin{array}{l}\text { S.D. Johnson 30xii99 s.n. } \\
\text { (NU); } 1\end{array}$ & $\begin{array}{l}\text { AY712547, AY712625, AY712586, XX, } \\
\text { XX }\end{array}$ \\
\hline Nycterinia & Z. microsiphon & 4 & $\begin{array}{l}28.9944 \mathrm{~S} \\
29.2272 \mathrm{E}\end{array}$ & $\begin{array}{l}\text { M.E. Mort, C.P. Randle, \& } \\
\text { J.K. Archibald 05.008; } 1\end{array}$ & $\mathbf{X X}, \mathbf{X X}, \mathbf{X X}, \mathbf{X X}, \mathbf{X X}$ \\
\hline Nycterinia & Z. microsiphon & 5 & $\begin{array}{l}29.8402 \mathrm{~S} \\
29.2142 \mathrm{E}\end{array}$ & J.K. Archibald 84 (OS); a & $\mathbf{X X}, \mathbf{X X}, \mathbf{X X}, \mathbf{X X}, \mathbf{X X}$ \\
\hline Nycterinia & Z. microsiphon & 6 & $\begin{array}{l}29.7417 \mathrm{~S} \\
29.1984 \mathrm{E}\end{array}$ & J.K. Archibald 89 (OS); a & $\mathbf{X X}, \mathbf{X X}, \mathbf{X X}, \mathbf{X X}, \mathbf{X X}$ \\
\hline Nycterinia & Z. microsiphon & $\mathbf{A 2}$ & $\begin{array}{l}28.6856 \mathrm{~S} \\
28.8981 \mathrm{E}\end{array}$ & B. Anderson 14 (STEU); 1 & $\mathbf{X X}, \mathbf{X X}, \mathbf{X X}, \mathbf{X X}, \mathbf{X X}$ \\
\hline Nycterinia & Z. microsiphon & $\mathbf{A 3}$ & $\begin{array}{l}28.7417 \mathrm{~S} \\
28.8917 \mathrm{E}\end{array}$ & B. Anderson 16 (STEU); 1 & $\mathbf{X X}, \mathbf{X X}, \mathbf{X X}, \mathbf{X X}, \mathbf{X X}$ \\
\hline Nycterinia & Z. microsiphon & A4 & $\begin{array}{l}29.2717 \mathrm{~S} \\
29.2715 \mathrm{E}\end{array}$ & B. Anderson 20 (STEU); 1 & $\mathbf{X X}, \mathbf{X X}, \mathbf{X X}, \mathbf{X X}, \mathbf{X X}$ \\
\hline Nycterinia & Z. microsiphon & A6 & $\begin{array}{l}29.5889 \mathrm{~S} \\
29.3083 \mathrm{E}\end{array}$ & B. Anderson 25 (STEU); 1 & $\mathbf{X X}, \mathbf{X X}, \mathbf{X X}, \mathbf{X X}, \mathbf{X X}$ \\
\hline Nycterinia & Z. microsiphon & A7 & $\begin{array}{l}29.6667 \mathrm{~S} \\
28.3667 \mathrm{E}\end{array}$ & B. Anderson s.n. (STEU); 1 & $\mathbf{X X}, \mathbf{X X}, \mathbf{X X}, \mathbf{X X}, \mathbf{X X}$ \\
\hline Nycterinia & Z. microsiphon & A8a & $29.8687 \mathrm{~S}$ & B. Anderson s.n. (STEU); 4 & $\mathbf{X X}, \mathbf{X X}, \mathbf{X X}, \mathbf{X X}, \mathbf{X X}$ \\
\hline
\end{tabular}




\begin{tabular}{|c|c|c|c|c|c|}
\hline Nycterinia & Z. microsiphon & A8b & $\begin{array}{l}29.1161 \mathrm{E} \\
29.8687 \mathrm{~S} \\
29.1161 \mathrm{E}\end{array}$ & B. Anderson s.n. (STEU); 1 & $\mathbf{X X}, \mathbf{X X}, \mathbf{X X}, \mathbf{X X}, \mathbf{X X}$ \\
\hline Nycterinia & Z. microsiphon & A9 & $\begin{array}{l}29.8747 \mathrm{~S} \\
29.7225 \mathrm{E}\end{array}$ & B. Anderson 17 (STEU); 1 & $\mathbf{X X}, \mathbf{X X}, \mathbf{X X}, \mathbf{X X}, \mathbf{X X}$ \\
\hline Nycterinia & Z. microsiphon & A10 & $\begin{array}{l}30.0525 \mathrm{~S} \\
28.9306 \mathrm{E}\end{array}$ & B. Anderson 19 (STEU); 1 & $\mathbf{X X}, \mathbf{X X}, \mathbf{X X}, \mathbf{X X}, \mathbf{X X}$ \\
\hline Nycterinia & Z. microsiphon & A11 & $\begin{array}{l}30.1361 \mathrm{~S} \\
28.6850 \mathrm{E}\end{array}$ & B. Anderson 24 (STEU); 1 & $\mathbf{X X}, \mathbf{X X}, \mathbf{X X}, \mathbf{X X}, \mathbf{X X}$ \\
\hline Nycterinia & Z. microsiphon & A12 & $\begin{array}{l}30.4028 \mathrm{~S} \\
28.8189 \mathrm{E}\end{array}$ & B. Anderson 15 (STEU); 4 & $\mathbf{X X}, \mathbf{X X}, \mathbf{X X}, \mathbf{X X}, \mathbf{X X}$ \\
\hline Nycterinia & Z. microsiphon & A13 & $\begin{array}{l}30.6639 \mathrm{~S} \\
29.5708 \mathrm{E}\end{array}$ & B. Anderson 22 (STEU); 1 & $\mathbf{X X}, \mathbf{X X}, \mathbf{X X}, \mathbf{X X}, \mathbf{X X}$ \\
\hline Nycterinia & Z. microsiphon & A14 & $\begin{array}{l}30.7292 \mathrm{~S} \\
28.1397 \mathrm{E}\end{array}$ & B. Anderson 26 (STEU); 1 & $\mathbf{X X}, \mathbf{X X}, \mathbf{X X}, \mathbf{X X}, \mathbf{X X}$ \\
\hline Nycterinia & Z. microsiphon & A15 & $\begin{array}{l}30.7584 \mathrm{~S} \\
28.2100 \mathrm{E}\end{array}$ & B. Anderson 23 (STEU); 11 & $\mathbf{X X}, \mathbf{X X}, \mathbf{X X}, \mathbf{X X}, \mathbf{X X}$ \\
\hline Nycterinia & Z. microsiphon & A16 & $\begin{array}{l}31.1833 \mathrm{~S} \\
27.5849 \mathrm{E}\end{array}$ & B. Anderson 18 (STEU); 1 & $\mathbf{X X}, \mathbf{X X}, \mathbf{X X}, \mathbf{X X}, \mathbf{X X}$ \\
\hline Nycterinia & $\begin{array}{l}\text { Z. natalensis Bernh. ex } \\
\text { Krause }\end{array}$ & 1 & $\begin{array}{l}29.8179 \mathrm{~S} \\
30.8026 \mathrm{E}\end{array}$ & J.K. Archibald 114 (OS); a & $\begin{array}{l}\text { AY712548, AY712626, AY712587, XX, } \\
\mathbf{X X}\end{array}$ \\
\hline Nycterinia & Z. ovata (Benth.) Walp. & 1 & $\begin{array}{l}29.4079 \mathrm{~S} \\
29.8918 \mathrm{E}\end{array}$ & J. K. Archibald 111 (OS); a & $\begin{array}{l}\text { AY712558, AY712636, AY712597, XX, } \\
\mathbf{X X}\end{array}$ \\
\hline Nycterinia & Z. ovata & 2 & $\begin{array}{l}29.2833 \mathrm{~S} \\
30.2833 \mathrm{E}\end{array}$ & J. Archibald $99(\mathrm{OS}) ; \mathrm{a}$ & $\mathbf{X X}, \mathbf{X X}, \mathbf{X X}, \mathbf{X X}, \mathbf{X X}$ \\
\hline Nycterinia & $\begin{array}{l}\text { Z. pachyrrhiza Hilliard \& } \\
\text { B.L. Burtt }\end{array}$ & 1 & $\begin{array}{l}\text { ca. } 27 \mathrm{~S} \\
32 \mathrm{E}\end{array}$ & S.D. Johnson 01 s.n. (NU); 1 & $\begin{array}{l}\text { AY712553, AY712631, AY712592, XX, } \\
\text { XX }\end{array}$ \\
\hline Nycterinia & Z. pulvinata Killick & 1 & $\begin{array}{l}29.2506 \mathrm{~S} \\
30.3182 \mathrm{E}\end{array}$ & $\begin{array}{l}\text { J.K. Archibald \& A.D. Wolfe } \\
5 \text { (OS); a }\end{array}$ & $\begin{array}{l}\text { AY712549, AY712627, AY712588, XX, } \\
\text { XX }\end{array}$ \\
\hline Nycterinia & Z. pulvinata & 2 & $\begin{array}{l}29.6004 \mathrm{~S} \\
29.3040 \mathrm{E}\end{array}$ & $\begin{array}{l}\text { J.K. Archibald \& A.D. Wolfe } \\
4 \text { (OS); a }\end{array}$ & $\mathbf{X X}, \mathbf{X X}, \mathbf{X X}, \mathbf{X X}, \mathbf{X X}$ \\
\hline Nycterinia & $\begin{array}{l}\text { Z. schmitziae Hilliard \& } \\
\text { B.L. Burtt }\end{array}$ & 1 & $\begin{array}{l}25.6839 \mathrm{~S} \\
28.0572 \mathrm{E}\end{array}$ & P. Burgoyne 24ii2005 s.n.; 1 & $\mathbf{X X}, \mathbf{X X}, \mathbf{X X}, \mathbf{X X}, \mathbf{X X}$ \\
\hline Nycterinia & Z. spathacea (Benth.) Walp. & 1 & $\begin{array}{l}24.9381 \mathrm{~S} \\
30.8544 \mathrm{E}\end{array}$ & $\begin{array}{l}\text { M.E. Mort, C.P. Randle, \& } \\
\text { J.K. Archibald } 05.071 \\
\text { (KANU); } 1\end{array}$ & $\mathbf{X X}, \mathbf{X X}, \mathbf{X X}, \mathbf{X X}, \mathbf{X X}$ \\
\hline Nycterinia & Z. tropicalis Hilliard & 1 & ca. $18 \mathrm{~S}$ & N.C. Chase $8390(\mathrm{~K})$; MWC & $\mathbf{X X}, \mathbf{X X},-, \mathbf{X X},-$ \\
\hline
\end{tabular}




\begin{tabular}{|c|c|c|c|c|c|}
\hline Reyemia & $\begin{array}{l}\text { Z. chasmanthiflora } \\
\text { (Hilliard) J.C. Manning \& } \\
\text { Goldblatt }\end{array}$ & 1 & $\begin{array}{l}32 \mathrm{E} \\
\text { ca. } 31 \mathrm{~S} \\
20 \mathrm{E}\end{array}$ & $\begin{array}{l}37673 \\
\text { A.U. Batten } 1016(\mathrm{~K}) \text {; MWC } \\
37674\end{array}$ & $\mathbf{X X}, \mathbf{X X}, \mathbf{X X},-, \mathbf{X X}$ \\
\hline Reyemia & Z. nemesioides Diels & 1 & $\begin{array}{l}31.7274 \mathrm{~S} \\
19.7864 \mathrm{E}\end{array}$ & A.D. Wolfe 986 (OS); 1 & $\begin{array}{l}\text { AY712582, AY712660, AY712621, XX, } \\
\text { XX }\end{array}$ \\
\hline Z. Noctiflora & Z. elgonensis Hedberg & 1 & $\begin{array}{l}\text { ca. } 3 \mathrm{~S} \\
37 \mathrm{E}\end{array}$ & Friis $241(\mathrm{~K})$; MWC 37671 & $\mathbf{X X}, \mathbf{X X}, \mathbf{X X}, \mathbf{X X},-$ \\
\hline Z. Noctiflora & $\begin{array}{l}\text { Z. peduncularis (Benth.) } \\
\text { Walp. }\end{array}$ & 1 & $\begin{array}{l}32.9090 \mathrm{~S} \\
20.6095 \mathrm{E}\end{array}$ & J.K. Archibald 45 (OS); a & $\begin{array}{l}\text { AY712568, AY712646, AY712607, XX, } \\
\text { XX }\end{array}$ \\
\hline Z. Noctiflora & Z. peduncularis & 2 & $\begin{array}{l}31.3549 \mathrm{~S} \\
19.8027 \mathrm{E}\end{array}$ & J.K. Archibald 23 (OS); 1 & $\mathbf{X X}, \mathbf{X X}, \mathbf{X X}, \mathbf{X X}, \mathbf{X X}$ \\
\hline Z. Noctiflora & Z. peduncularis & 3 & $\begin{array}{l}33.7299 \mathrm{~S} \\
23.0444 \mathrm{E}\end{array}$ & $\begin{array}{l}\text { J.K. Archibald \& M.E. Mort } \\
242 \text { (KANU); } 2\end{array}$ & $\mathbf{X X}, \mathbf{X X}, \mathbf{X X}, \mathbf{X X}, \mathbf{X X}$ \\
\hline Z. Zaluzianskya & Z. affinis Hilliard & 1 & $\begin{array}{l}31.6002 \mathrm{~S} \\
18.7549 \mathrm{E}\end{array}$ & J.K. Archibald $9(\mathrm{OS}) ; 1$ & $\begin{array}{l}\text { AY712561, AY712639, AY712600, XX, } \\
\text { XX }\end{array}$ \\
\hline Z. Zaluzianskya & Z. affinis & 2 & $\begin{array}{l}31.5958 \mathrm{~S} \\
18.4389 \mathrm{E}\end{array}$ & J.K. Archibald 29 (OS); 1 & $\begin{array}{l}\text { AY712562, AY712640, AY712601, XX, } \\
\text { XX }\end{array}$ \\
\hline Z. Zaluzianskya & Z. affinis & 3 & $\begin{array}{l}29.1210 \mathrm{~S} \\
16.8468 \mathrm{E}\end{array}$ & J.K. Archibald 14 (OS); 1 & $\mathbf{X X}, \mathbf{X X}, \mathbf{X X}, \mathbf{X X}, \mathbf{X X}$ \\
\hline Z. Zaluzianskya & Z. affinis & 4 & $\begin{array}{l}30.5828 \mathrm{~S} \\
17.5403 \mathrm{E}\end{array}$ & K.E. Steiner 3358 (NBG); 1 & $\mathbf{X X}, \mathbf{X X}, \mathbf{X X}, \mathbf{X X}, \mathbf{X X}$ \\
\hline Z. Zaluzianskya & Z. bella Hilliard & 1 & $\begin{array}{l}32.9090 \mathrm{~S} \\
20.6095 \mathrm{E}\end{array}$ & J.K. Archibald 44 (OS); a & $\begin{array}{l}\text { AY712564, AY712642, AY712603, XX, } \\
\text { XX }\end{array}$ \\
\hline Z. Zaluzianskya & Z. bella & 2 & $\begin{array}{l}32.8732 \mathrm{~S} \\
20.6712 \mathrm{E}\end{array}$ & J.K. Archibald 50 (OS); a & $\mathbf{X X}, \mathbf{X X}, \mathbf{X X}, \mathbf{X X}, \mathbf{X X}$ \\
\hline Z. Zaluzianskya & Z. cohabitans Hilliard & 1 & $\begin{array}{l}32.9090 \mathrm{~S} \\
20.6095 \mathrm{E}\end{array}$ & J.K. Archibald 46 (OS); 1 & $\begin{array}{l}\text { AY712567, AY712645, AY712606, XX, } \\
\text { XX }\end{array}$ \\
\hline Z. Zaluzianskya & Z. cohabitans & 2 & $\begin{array}{l}32.3006 \mathrm{~S} \\
20.3880 \mathrm{E}\end{array}$ & J.K. Archibald 60 (OS); 2 & $\mathbf{X X}, \mathbf{X X}, \mathbf{X X}, \mathbf{X X}, \mathbf{X X}$ \\
\hline Z. Zaluzianskya & Z. gracilis Hilliard & 1 & $\begin{array}{l}34.4758 \mathrm{~S} \\
20.5095 \mathrm{E}\end{array}$ & J.K. Archibald $6.2(\mathrm{OS})$; a & $\begin{array}{l}\text { AY712563, AY712641, AY712602, XX, } \\
\text { XX }\end{array}$ \\
\hline Z. Zaluzianskya & Z. gracilis & 2 & $\begin{array}{l}34.7111 \mathrm{~S} \\
20.1036 \mathrm{E}\end{array}$ & $\begin{array}{l}\text { J.K. Archibald \& M.E. Mort } \\
192 \text { (KANU); } 1\end{array}$ & $\mathbf{X X}, \mathbf{X X}, \mathbf{X X}, \mathbf{X X}, \mathbf{X X}$ \\
\hline Z. Zaluzianskya & Z. gracilis & 3 & $\begin{array}{l}34.3208 \mathrm{~S} \\
21.5034 \mathrm{E}\end{array}$ & $\begin{array}{l}\text { J.K. Archibald \& M.E. Mort } \\
263 \text { (KANU); } 1\end{array}$ & $\mathbf{X X}, \mathbf{X X}, \mathbf{X X}, \mathbf{X X}, \mathbf{X X}$ \\
\hline Z. Zaluzianskya & Z. minima (Hiern) Hilliard & 1 & $32.2084 \mathrm{~S}$ & J.K. Archibald 58 (OS); a & AY712566, AY712644, AY712605, XX, \\
\hline
\end{tabular}




\begin{tabular}{|c|c|c|c|c|c|}
\hline & & & $20.4257 \mathrm{E}$ & & $\mathbf{X X}$ \\
\hline Z. Zaluzianskya & Z. minima & 2 & $\begin{array}{l}31.7268 \mathrm{~S} \\
20.0495 \mathrm{E}\end{array}$ & K.E. Steiner 3396 (NBG); 1 & $\mathbf{X X}, \mathbf{X X}, \mathbf{X X}, \mathbf{X X}, \mathbf{X X}$ \\
\hline Z. Zaluzianskya & Z. villosa F.W. Schmidt & 1 & $\begin{array}{l}34.5647 \mathrm{~S} \\
19.3528 \mathrm{E}\end{array}$ & J.K. Archibald 1 (OS); 1 & $\begin{array}{l}\text { AY712560, AY712638, AY712599, XX, } \\
\text { XX }\end{array}$ \\
\hline Z. Zaluzianskya & Z. villosa & 2 & $\begin{array}{l}34.3123 \mathrm{~S} \\
18.4508 \mathrm{E}\end{array}$ & $\begin{array}{l}\text { J.K. Archibald \& M.E. Mort } \\
155 \text { (KANU); } 1\end{array}$ & $\mathbf{X X}, \mathbf{X X}, \mathbf{X X}, \mathbf{X X}, \mathbf{X X}$ \\
\hline Z. Zaluzianskya & Z. violacea Schlt. & 1 & $\begin{array}{l}31.6359 \mathrm{~S} \\
19.8963 \mathrm{E}\end{array}$ & J.K. Archibald 18 (OS); 1 & $\begin{array}{l}\text { AY712565, AY712643, AY712604, XX, } \\
\text { XX }\end{array}$ \\
\hline Z. Zaluzianskya & Z. violacea & 2 & $\begin{array}{l}31.4290 \mathrm{~S} \\
19.7844 \mathrm{E}\end{array}$ & J.K. Archibald 17.1 (OS); 1 & $\mathbf{X X}, \mathbf{X X}, \mathbf{X X}, \mathbf{X X}, \mathbf{X X}$ \\
\hline Z. Zaluzianskya & Z. violacea & 3 & $\begin{array}{l}29.7589 \mathrm{~S} \\
17.9352 \mathrm{E}\end{array}$ & J.K. Archibald 15 (OS); 1 & $\mathbf{X X}, \mathbf{X X}, \mathbf{X X}, \mathbf{X X}, \mathbf{X X}$ \\
\hline $\begin{array}{l}\text { Subgenus } \\
\text { Leiospermum }\end{array}$ & $\begin{array}{l}\text { Phyllopodium cf. } \\
\text { cephalophorum (Thunb.) } \\
\text { Hilliard }\end{array}$ & GB & & & AJ584751, AJ401447, -, -, - \\
\hline $\begin{array}{l}\text { Subgenus } P h \text {. } \\
\text { Subgroup 2A }\end{array}$ & $\begin{array}{l}\text { Phyllopodium cordatum } \\
\text { (Thunb.) Hilliard }\end{array}$ & 1 & $\begin{array}{l}34.5392 \mathrm{~S} \\
20.0344 \mathrm{E}\end{array}$ & $\begin{array}{l}\text { J.K. Archibald \& M.E. Mort } \\
179 \text { (KANU); } 1\end{array}$ & $\mathbf{X X}, \mathbf{X X}, \mathbf{X X}, \mathbf{X X}, \mathbf{X X}$ \\
\hline $\begin{array}{l}\text { Subgenus } P h \text {. } \\
\text { Subgroup 1A }\end{array}$ & $\begin{array}{l}\text { Phyllopodium cuneifolium } \\
\text { (L.f.) Benth. }\end{array}$ & 1 & $\begin{array}{l}\text { ca. } 33.5 \mathrm{~S} \\
27.1 \mathrm{E}\end{array}$ & $\begin{array}{l}\text { J.K. Archibald \& M.E. Mort } \\
229 \text { (KANU); } 1\end{array}$ & $\mathbf{X X}, \mathbf{X X}, \mathbf{X X}, \mathbf{X X}, \mathbf{X X}$ \\
\hline $\begin{array}{l}\text { Subgenus } P h . \\
\text { Subgroup 1A }\end{array}$ & Phyllopodium cuneifolium & GB & & &,- AJ296496, -, -, - \\
\hline $\begin{array}{l}\text { Subgenus } P h \text {. } \\
\text { Subgroup 1B }\end{array}$ & $\begin{array}{l}\text { Phyllopodium dolomiticum } \\
\text { Hilliard }\end{array}$ & GB & & & AJ584806, AJ586087, -, -, - \\
\hline $\begin{array}{l}\text { Subgenus } P h . \\
\text { Subgroup } 2 \mathrm{~A}\end{array}$ & $\begin{array}{l}\text { Phyllopodium mimetes } \\
\text { Hilliard }\end{array}$ & $\mathbf{1}$ & $\begin{array}{l}34.0492 \mathrm{~S} \\
18.6688 \mathrm{E}\end{array}$ & A.D. Wolfe 936 (OS); 1 & $\mathbf{X X}, \mathbf{X X},-,-,-$ \\
\hline $\begin{array}{l}\text { Subgenus } P h \text {. } \\
\text { Subgroup 1B }\end{array}$ & $\begin{array}{l}\text { Phyllopodium multifolium } \\
\text { Hiern }\end{array}$ & GB & & & AJ584802, AJ586085, -, -, - \\
\hline Subgenus $P h$. & $\begin{array}{l}\text { Phyllopodium rustii (Rolfe) } \\
\text { Hilliard }\end{array}$ & 1 & $\begin{array}{l}33.5147 \mathrm{~S} \\
22.3363 \mathrm{~F}\end{array}$ & J.K. Archibald \& M.E. Mort & $\mathbf{X X}, \mathbf{X X}, \mathbf{X X}, \mathbf{X X}, \mathbf{X X}$ \\
\hline- & $\begin{array}{l}\text { Aptosimum indivisum } \\
\text { Burch. ex Benth. }\end{array}$ & 1 & $\begin{array}{l}33.1267 \mathrm{~S} \\
21.2054 \mathrm{E}\end{array}$ & A.D. Wolfe 910 (OS); 1 & AY712574, AY712652, AY712613,-,-- \\
\hline- & $\begin{array}{l}\text { Aptosimum procumbens } \\
\text { (Lehm.) Steud. }\end{array}$ & 1 & $\begin{array}{l}\text { Karoo } \\
\text { Botanical } \\
\text { Garden }\end{array}$ & A.D. Wolfe 685 (OS); 1 & AY712573, AY712651, AY712612,-,-- \\
\hline- & $\begin{array}{l}\text { Barthlottia } \\
\text { madagascariensis Eb. Fisch. }\end{array}$ & GB & & & AJ550576, AJ401444, -, -, - \\
\hline
\end{tabular}




\begin{tabular}{|c|c|c|c|c|c|}
\hline- & Chaenostoma hispidum & 1 & $\begin{array}{l}34.1683 \mathrm{~S} \\
18.3441 \mathrm{E}\end{array}$ & A.D. Wolfe $930(\mathrm{OS}) ; 1$ & AY712583, AY712661, AY712622,-,- \\
\hline- & $\begin{array}{l}\text { Chaenostoma patrioticum } \\
\text { (Hiern) Kornhall }\end{array}$ & GB & & & AJ550612, AJ551261,-, -, - \\
\hline- & $\begin{array}{l}\text { Chenopodiopsis retrorsa } \\
\text { Hilliard }\end{array}$ & GB & & & AJ584757, AJ296502,-, -, - \\
\hline- & $\begin{array}{l}\text { Cromidon decumbens } \\
\text { (Thunb.) Hilliard }\end{array}$ & GB & & & AJ584756, AJ296503,-, -, - \\
\hline- & $\begin{array}{l}\text { Dischisma ciliatum (Berg.) } \\
\text { Choisy }\end{array}$ & GB & & &,- AJ296501, -, -, - \\
\hline- & Dischisma spicatum Choisy & GB & & & AJ584823, AJ586098, -, -, - \\
\hline- & $\begin{array}{l}\text { Glekia krebsiana (Benth.) } \\
\text { Hilliard }\end{array}$ & GB & & &,- AJ296519, -, -, - \\
\hline- & $\begin{array}{l}\text { Glumicalyx flanaganii } \\
\text { (Hiern) Hilliard \& B.L. } \\
\text { Burtt }\end{array}$ & 1 & $\begin{array}{l}\text { ca. } 29.5 \mathrm{~S} \\
29.2 \mathrm{E}\end{array}$ & T.J. Edwards 1774 (NU); 1 & AY712575, AY712653, AY712614,-,-- \\
\hline- & $\begin{array}{l}\text { Glumicalyx goseloides } \\
\text { (Diels) Hilliard \& B.L. Burtt }\end{array}$ & 1 & $\begin{array}{l}\text { Not } \\
\text { available }\end{array}$ & $\begin{array}{l}\text { K.E. Steiner } 4 \text { ii } 98 \text { s. n. } \\
\text { (NBG); } 1\end{array}$ & $\begin{array}{l}\text { AY712576, AY712654, AY712615, XX, } \\
\text { XX }\end{array}$ \\
\hline- & Hebenstretia dura Choisy & GB & & & AJ584821, AJ586097, -, -, - \\
\hline- & $\begin{array}{l}\text { Hebenstretia lanceolata } \\
\text { Rolfe }\end{array}$ & GB & & & AJ584825, AJ586100, -, -, - \\
\hline- & $\begin{array}{l}\text { Jamesbrittenia adpressa } \\
\text { (Dinter) Hilliard }\end{array}$ & 1 & $\begin{array}{l}\text { ca. } 29.5 \mathrm{~S} \\
19.4 \mathrm{E}\end{array}$ & D.A. Snijman 1851 (NBG); 1 & AY712577, AY712655, AY712616,-,-- \\
\hline- & $\begin{array}{l}\text { Jamesbrittenia filicaulis } \\
\text { (Benth.) Hilliard }\end{array}$ & GB & & &,- AJ621112,-, -, - \\
\hline- & $\begin{array}{l}\text { Jamesbrittenia megadenia } \\
\text { Hilliard }\end{array}$ & GB & & & AJ550584, AJ296511, -, -, - \\
\hline- & $\begin{array}{l}\text { Limosella grandiflora } \\
\text { Benth. }\end{array}$ & GB & & & AJ550587, AJ550525, -, -, - \\
\hline- & $\begin{array}{l}\text { Limosella macrantha R.E. } \\
\text { Fr. }\end{array}$ & GB & & & AJ550586, AJ550526, -, -, - \\
\hline- & $\begin{array}{l}\text { Lyperia antirrhinoides (L.f.) } \\
\text { Hilliard }\end{array}$ & GB & & & AJ616324, AJ621123,-,-, - \\
\hline- & Lyperia tristis (L.f.) Benth. & 1 & $\begin{array}{l}31.7267 \mathrm{~S} \\
18.6667 \mathrm{E}\end{array}$ & A.D. Wolfe $879(\mathrm{OS}) ; 1$ & AY712578, AY712656, AY712617, -, - \\
\hline- & Lyperia tristis & GB & & & AJ550589, AJ550527, -, -, - \\
\hline- & Manulea altissima $\mathrm{L}$. f. & 1 & $31.7267 \mathrm{~S}$ & A.D. Wolfe $708(\mathrm{OS}) ; 1$ & AY712579, AY712657, AY712618, -,-- \\
\hline
\end{tabular}




\begin{tabular}{|c|c|c|c|c|c|}
\hline & & & $18.6667 \mathrm{E}$ & & \\
\hline- & Manulea calciphila Hilliard & GB & & & AJ550592, AJ550533, -, -, - \\
\hline- & $\begin{array}{l}\text { Manulea chrysantha } \\
\text { Hilliard }\end{array}$ & GB & & & AJ550595, AJ550532, -, -, - \\
\hline- & Manulea rubra (Berg.) L. f. & 1 & $\begin{array}{l}32.6203 \mathrm{~S} \\
19.1170 \mathrm{E}\end{array}$ & A.D. Wolfe 718 (OS); 1 & AY712580, AY712658, AY712619,-,- \\
\hline- & $\begin{array}{l}\text { Melanospermum foliosum } \\
\text { (Benth.) Hilliard }\end{array}$ & GB & & & AJ584753, AJ296507, -, -, - \\
\hline- & $\begin{array}{l}\text { Melanospermum } \\
\text { transvaalense (Hiern) } \\
\text { Hilliard }\end{array}$ & GB & & & AJ584759, AJ296508, -, -, - \\
\hline- & $\begin{array}{l}\text { Microdon dubius (L.) } \\
\text { Hilliard }\end{array}$ & GB & & & AJ584792, AJ586079, -, -, -- \\
\hline- & $\begin{array}{l}\text { Microdon orbicularis } \\
\text { Choisy }\end{array}$ & GB & & & AJ584762, AJ586053,-,-, - \\
\hline- & Polycarena aurea Benth. & 1 & $\begin{array}{l}32.3260 \mathrm{~S} \\
20.1354 \mathrm{E}\end{array}$ & A.D. Wolfe 979 (OS); 1 & $\begin{array}{l}\text { AY712581, AY712659, AY712620, XX, } \\
\text { XX }\end{array}$ \\
\hline- & $\begin{array}{l}\text { Polycarena batteniana } \\
\text { Hilliard }\end{array}$ & GB & & & AJ584769, AJ586059, -, -, - \\
\hline- & $\begin{array}{l}\text { Polycarena capensis }(\mathrm{L} .) \\
\text { Benth. }\end{array}$ & GB & & &,- AJ586050, -, -, - \\
\hline- & Polycarena filiformis Diels & GB & & & AJ584807, AJ586088,,,---- \\
\hline - & Polycarena formosa Hilliard & GB & & & AJ584754, AJ296515, -, -, - \\
\hline- & $\begin{array}{l}\text { Polycarena pubescens } \\
\text { Benth. }\end{array}$ & GB & & & AJ584768, -,-, -, - \\
\hline- & $\begin{array}{l}\text { Pseudoselago ascendens (E. } \\
\text { Mey.) Hilliard }\end{array}$ & GB & & &,- AJ296495, -, -, - \\
\hline- & $\begin{array}{l}\text { Pseudoselago densifolia } \\
\text { (Hochst.) Hilliard }\end{array}$ & GB & & & AJ584799, AJ586082, -, -, - \\
\hline- & $\begin{array}{l}\text { Pseudoselago recurvifolia } \\
\text { Hilliard }\end{array}$ & GB & & & AJ584801, AJ586084, -, -, - \\
\hline- & Selago canescens L.f. & GB1 & & &,- AJ608637, -, -,-- \\
\hline- & Selago canescens & GB2 & & & AJ584772,-,-,-,- \\
\hline - & Selago foliosa Rolfe & GB & & & AJ584786, AJ586073,-,-,- \\
\hline- & Selago venosa Hilliard & GB & & & AJ584778, AJ586066, -, -, - \\
\hline- & Sutera foetida Roth & GB & & & AJ550609, AJ296510,-,-,- \\
\hline- & Tetraselago longituba & GB & & & AJ584826, AJ296506, -, -,-- \\
\hline
\end{tabular}




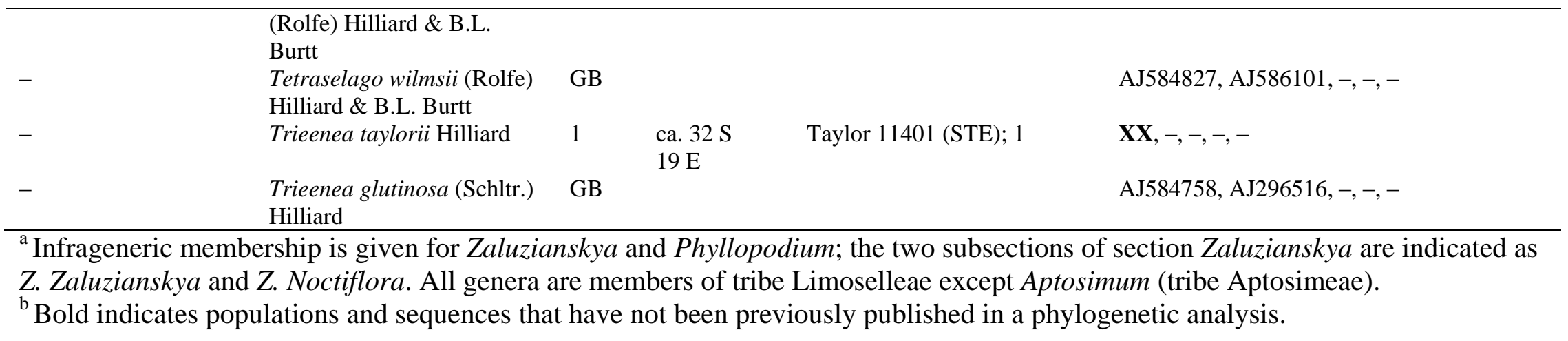




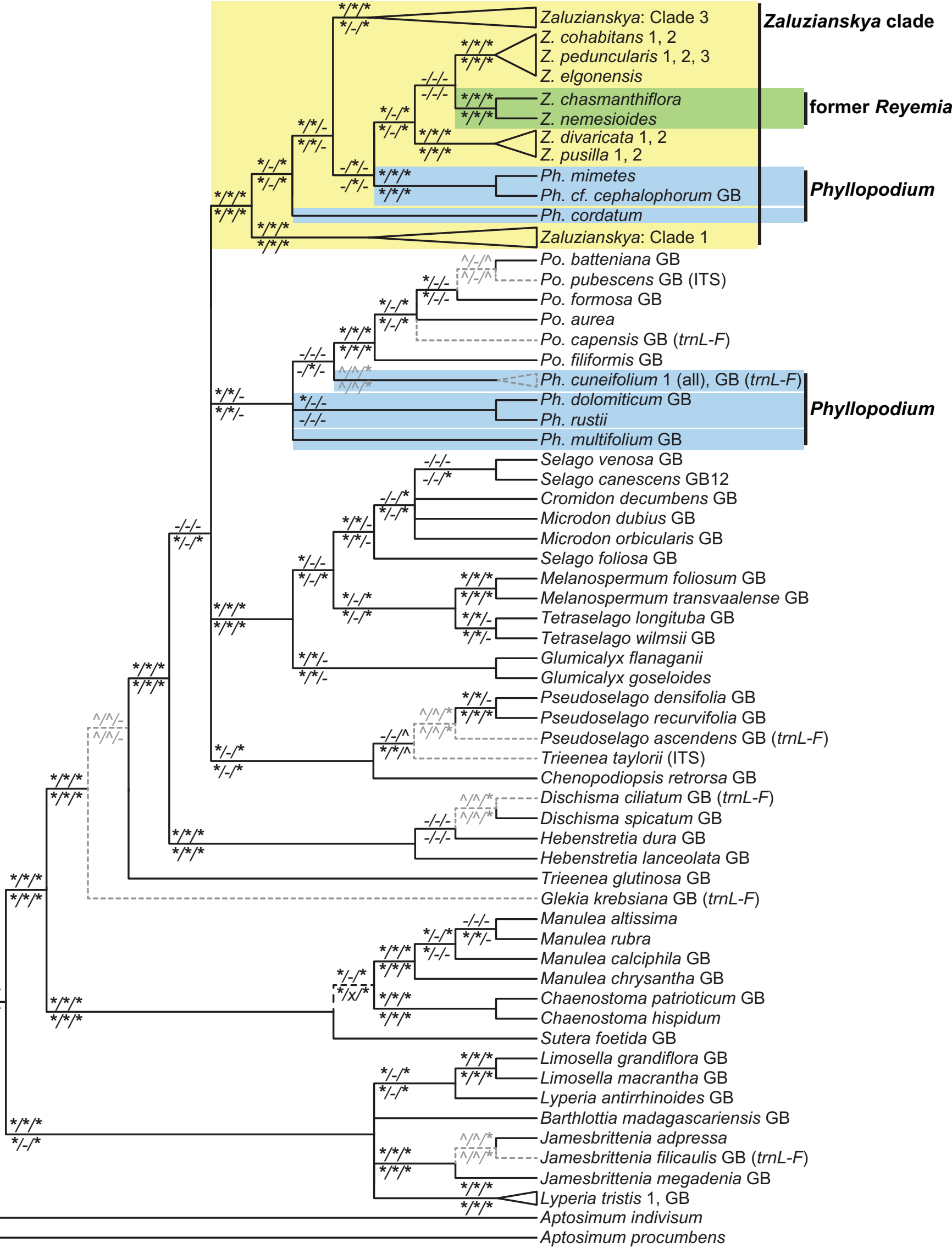


${ }^{* /-/-} \longrightarrow$ Z. glareosa 1, 2

Z. microsiphon 1, 4, A2, A3, A7

Z. microsiphon A9, A10

Z. elongata 1, 2

Z. microsiphon A12

Z. pachyrrhiza

Z. schmitziae

Z. microsiphon A8a, A8b

Z. katharinae

Z. spathacea

Z. microsiphon 2, 6, A6

Z. pulvinata 2

Clade $\frac{*-/{ }^{*}}{-/ /^{*}}$

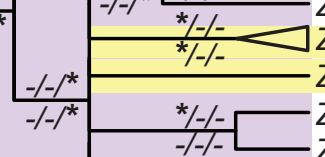

Z. microsiphon 5, A11, A13

Z. microsiphon A4

3B

*1

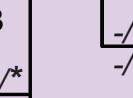

$* /-{ }^{*}$

$-1--$

Z. pulvinata 1

Z. elongata 3

Z. natalensis

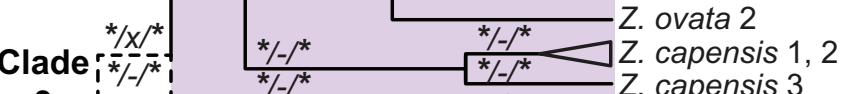

$31, \quad$ Z capensis 3

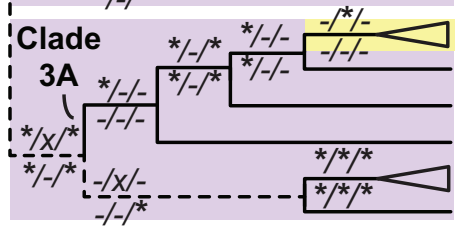

Z. microsiphon-S: 3, A14, A15, A16

Z. angustifolia 1

Z. angustifolia 2

Z. maritima 2

Z. mirabilis 1, 2

Z. maritima 1

Z. tropicalis

$* * * *$

Z. cohabitans 1,2

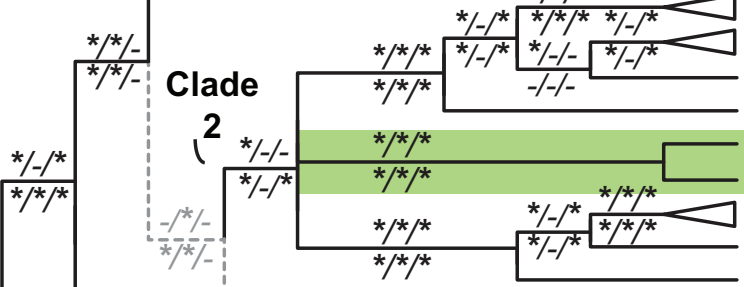

Z. peduncularis 1, 2

Z. peduncularis 3

Z. elgonensis

Z. chasmanthiflora

Z. nemesioides

Z. divaricata 1, 2

Z. pusilla 1

Z. pusilla 2

Clade

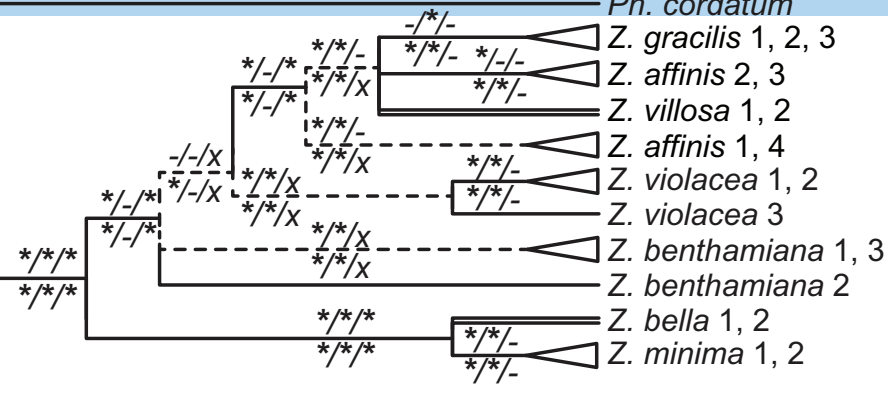

Ph. cf. cephalophorum GB (level 3) 
Z. microsiphon (17 pops.),

Z. capensis, Z. elongata, Z. glareosa, Z. katharinae,

Z. natalensis, Z. ovata, Z. pachyrrhiza, Z. pulvinata,

Z. schmitziae, Z. spathacea

Z. microsiphon-S (4 pops.),

Z. angustifolia, Z. maritima, Z. mirabilis

Z. tropicalis

Z. cohabitans, Z. elgonensis, Z. peduncularis

Z. chasmanthiflora

former Reyemia

Z. nemesioides

Z. divaricata, Z. pusilla

Ph. mimetes

Ph. cf. cephalophorum

Phyllopodium

Ph. cordatum

Zaluzianskya: Clade 1

Polycarena

Ph. cuneifolium, Ph. dolomiticum

Ph. multifolium, Ph. rustii

Zaluzianskya clade

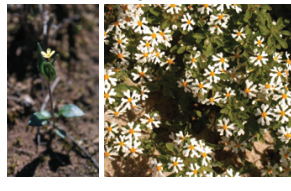

